\title{
The Effects of Intrinsic Foot Muscle Strengthening on Foot Posture, Balance, and Agility in Ice Hockey Players
}

\author{
Rebecca Eve Veltrie \\ rev0005@mix.wvu.edu
}

Follow this and additional works at: https://researchrepository.wvu.edu/etd

Part of the Musculoskeletal System Commons, and the Rehabilitation and Therapy Commons

\section{Recommended Citation}

Veltrie, Rebecca Eve, "The Effects of Intrinsic Foot Muscle Strengthening on Foot Posture, Balance, and Agility in Ice Hockey Players" (2020). Graduate Theses, Dissertations, and Problem Reports. 7602. https://researchrepository.wvu.edu/etd/7602

This Thesis is protected by copyright and/or related rights. It has been brought to you by the The Research Repository @ WVU with permission from the rights-holder(s). You are free to use this Thesis in any way that is permitted by the copyright and related rights legislation that applies to your use. For other uses you must obtain permission from the rights-holder(s) directly, unless additional rights are indicated by a Creative Commons license in the record and/ or on the work itself. This Thesis has been accepted for inclusion in WVU Graduate Theses, Dissertations, and Problem Reports collection by an authorized administrator of The Research Repository @ WVU. For more information, please contact researchrepository@mail.wvu.edu. 
The Effects of Intrinsic Foot Muscle Strengthening on Foot Posture, Balance, and Agility in Ice Hockey Players

Rebecca Eve Veltrie

Follow this and additional works at: https://researchrepository.wvu.edu/etd

Part of the Musculoskeletal System Commons, and the Rehabilitation and Therapy Commons 
The Effects of Intrinsic Foot Muscle Strengthening on Foot Posture, Balance, and Agility in Ice Hockey Players

Rebecca E. Veltrie, ATC

Thesis submitted to the

College of Physical Activity and Sport Sciences

at West Virginia University

In partial fulfillment of the requirements

for the degree of

Master of Science in Athletic Training

Michelle A. Sandrey, PhD, ATC, Chair

Greg Dahmer MA, ATC-RET, BOC-Orthotist

Jean McCrory, PhD

Department of Athletic Training

Morgantown, West Virginia

2020

Keywords: Intrinsic Muscles, Extrinsic Muscles, Foot Core, Star Excursion Balance Test, Navicular Drop, FAAM Sport and FAAM ADL

Copyright 2020 Rebecca Veltrie 
ABSTRACT

The Effects of Intrinsic Foot Muscle Strengthening on Foot Posture, Balance, and Agility in Ice Hockey Players

Rebecca E. Veltrie, ATC

Context: Research has shown that intrinsic foot muscle strengthening over a 4-week period is beneficial for improvements in dynamic postural control, function, stability and foot posture. Ice hockey is a sport that requires immense levels of balance, stability and performance on the lateral aspect of the skate. With research lacking on the impact of intrinsic foot muscle strengthening on ice hockey athletes' balance, foot posture and performance, implementation of such a program may be beneficial for ice hockey players. Objective: The purpose of this study was to explore the effects of foot intrinsic muscle strengthening versus a traditional extrinsic muscle strengthening program on ice hockey players balance, foot posture, agility and perceived ability.

Design: Randomized superiority study. Setting: D1 and D2 men's university club ice hockey teams in a mid-Atlantic state. Patients or Other Participants: Twenty-eight subjects (Age=19.96 $\pm 1.59 \mathrm{yrs}$; height $=180.56 \pm 6.70 \mathrm{~cm}$; mass $=79.04 \pm 9.06 \mathrm{~kg}$ ) that participate on the D1 or D2

men's university club ice hockey teams volunteered for this study. All participants met inclusion criteria. Inclusion criteria included subjects who are healthy, currently on the roster for the men's D1 or D2 club ice hockey teams, no history of a serious injury to the ankle or foot in the past six months, and no history of surgeries to the lower extremity within the last 6 months. Exclusion criteria included a history of surgery to the lower extremity within the last 6 months, history of a serious injury to the lower extremity within the last 6 months, and those who had a disorder that may affect ability to perform any of the procedures within the study. One participant was excluded due to having mononucleosis at the time of pre-testing and another dropped out due to school obligations. Interventions: Subjects were randomly assigned to the Foot Core Interventions group or the Traditional Exercise group. The Foot Core exercise group performed the short foot and the toes-spread-out exercises throughout a 4-week period for two sessions per week. The Traditional exercise group performed towel scrunches and marble pick-

ups throughout a 4-week period for two sessions per week. Both groups completed pre- and posttest measurements of Foot and Ankle Ability Measures (FAAM) for ADL and Sport, the navicular drop test, the Star Excursion Balance Test (SEBT) in Anterior (A), Posterolateral (PL) and Posteromedial (PM) directions, and the S-Cornering agility drill. Main Outcome Measures: FAAM ADL and Sport, the navicular drop test, SEBT (A, PM, and PL), and the S-Cornering ice hockey drill. Results: Navicular drop demonstrated a significant change for test for the left limb $(\mathrm{p}<.001,-.02(-1.85$ to -.85$)$ and the right limb $(\mathrm{p}<.001,-.24(-1.84$ to -.2$)$ in both groups. The A direction of the SEBT showed a significant change for limb $(\mathrm{p}=.032)$ and test by group $(\mathrm{p}$ $=.024)$, for the left limb (.26(-.51 to 1.04)) and right limb (.5(-.72 to .82)) for the traditional group. The PM direction showed a significant change for test $(\mathrm{p}<.001)$ and limb by test $(\mathrm{p}$ $=.031)$, for the left limb (.52(-.26 to 1.3)) and right limb (.78(-.02 to 1.57)) in both groups. The PL direction showed a significant change for test for the left limb $(\mathrm{p}=.001, .05(-.72$ to .82$))$ and the right limb $(\mathrm{p}=.001, .35(-.42$ to 1.13$))$ in both groups. The S-Cornering agility test showed a significant change for test ( $\mathrm{p}<.001, .09(-.7$ to .87$))$ for both groups. There was a significant limb main effect for both groups and a significant test by group interaction for right $\mathrm{A}$ and left $\mathrm{A}$. Conclusions: With both groups demonstrating significant changes in all clinically oriented outcomes, it can be determined that a 4-week program for both the short foot exercises and traditional exercises can provide a positive impact on balance, foot posture and agility within ice hockey athletes. 


\section{ACKNOWLEDGMENTS}

I would like to thank my family, especially my mom and dad, for always believing in me and for their constant support throughout everything I do.

I would like to thank the Athletic Training faculty at Ithaca College for giving me an abundance of knowledge and creating my passion for athletic training.

I would like to thank the WVU men's club ice hockey teams for their participation and for constantly showing me support. They made this process enjoyable and fun for me and I cannot thank them enough for the past 2 years.

I would like to thank Dr. Michelle Sandrey for her help with this study. Without her guidance, this study would have been difficult to complete.

I would also like to thank Jean McCrory and Greg Dahmer for taking the time to be a part of my committee as well as help guide me throughout this process. 


\section{TABLE OF CONTENTS}

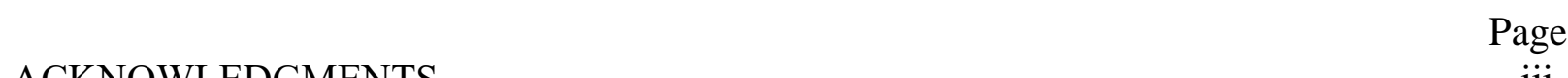

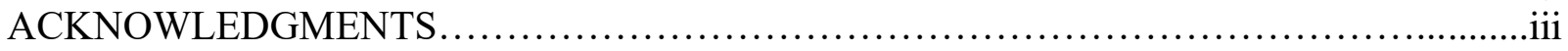

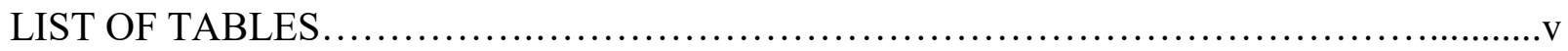

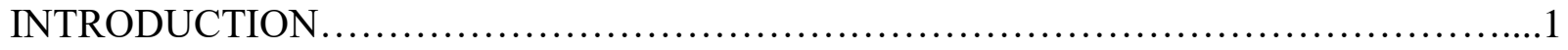

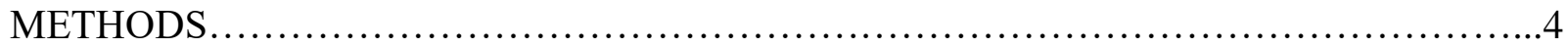

RESULTS.................................................................. 14

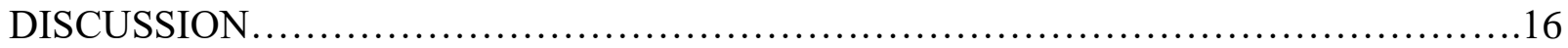

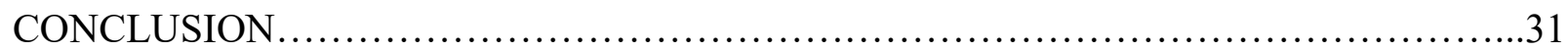

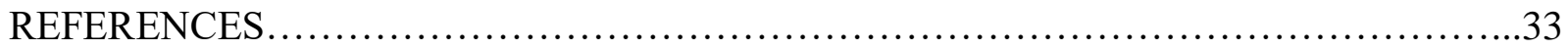

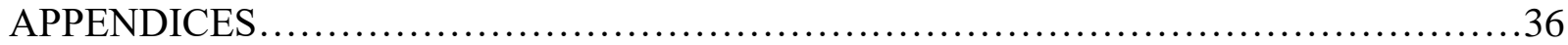

APPENDIX A. THE PROBLEM............................................. 37

APPENDIX B. LITERATURE REVIEW ....................................46

APPENDIX C. ADDITIONAL METHODS ..........................................74

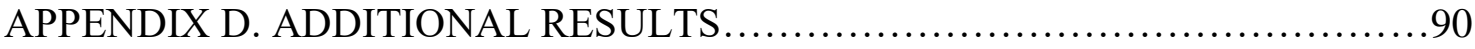

APPENDIX E. RECOMMENDATION FOR FUTURE RESEARCH.................91

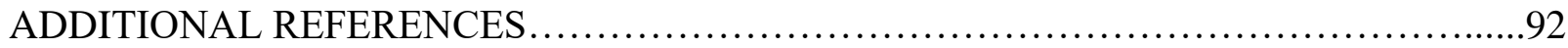




\section{LIST OF TABLES}

TABLES Page

B1. Extrinsic Muscles of the Foot................................................... 51

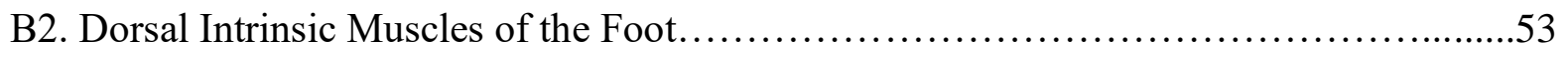

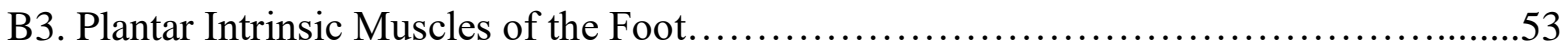

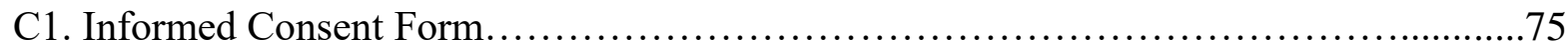

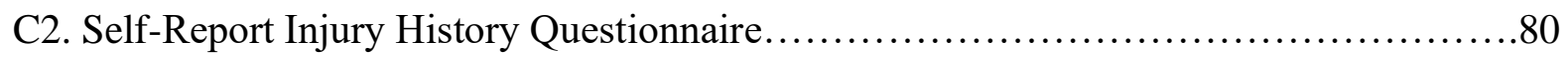

C3. Foot and Ankle Ability Measure (FAAM) ADL and Sport............................ 81

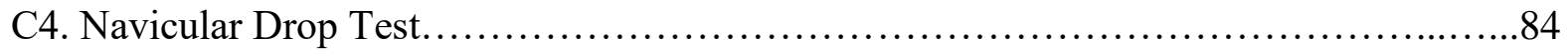

C5. Star Excursion Balance Test (SEBT) Anterior, Posteromedial and Posterolateral.........84

C6. Ice Hockey S-Cornering Agility Drill ........................................... 86

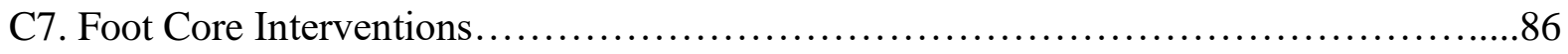

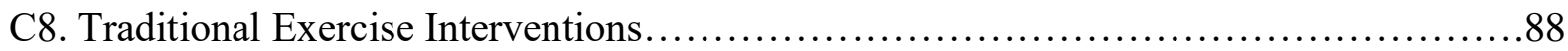

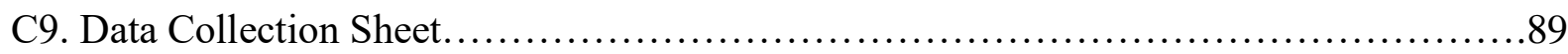

D1. Self-Reported Function Scores (Means \pm SD) and Hedges g Group Effect Sizes With 95\%

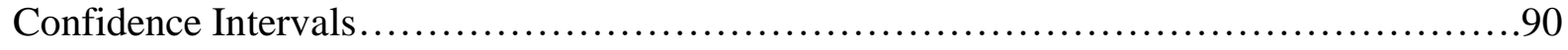

D2. Navicular Drop, Star Excursion Balance Test, and Agility (Means \pm SD) and Hedges $g$ Group Effect Sizes With 95\% Confidence Intervals..................................... 90 


\section{INTRODUCTION}

The foot is a flexible structure that adapts to loads to become a shock absorber or rigid lever.1 Because of this, as well as being the most distal part of the leg, the foot is the primary structure responsible for weight bearing activities, force dispersion, gait patterns, postural stability and general movement.2-5 For this to occur, there are multiple structures that allow this to transpire. These include bones, ligaments, and muscles.2,3,6,7 Of these three, the most important structures to understand and differentiate are the muscles due to the role in biomechanics. This is due to the muscles' roles in many biomechanical aspects of the foot. The muscles of the foot can be categorized into extrinsic and intrinsic muscle groups. Each group provides a unique quality to the foot and allows for different properties to occur.4,5,8

The extrinsic group consists of the muscles that originate in the lower leg portion of the body and cross the ankle joint to insert on the foot. 4 The extrinsic muscles primarily function as global movers. With being a global mover, the extrinsic muscles generate larger movements compared to intrinsic muscles. The extrinsic muscles also consist of large cross-sectional areas and large moment arms, which allow absorption and propulsion during the gait phases, and provide slight support to the medial longitudinal arch (MLA).4,5,8 In a different regard, the intrinsic muscles allow for primary stabilization to occur at the foot.4 These muscles all originate and insert on the plantar or dorsal surface of the foot, not crossing the ankle joint.4,6 Through small moment arms and cross-sectional areas, the intrinsic muscles provide some different aspects to the foot when compared to the extrinsic muscle group. $4,5,8$ The intrinsic muscles act as the primary stabilizers through support of the arches of the foot, therefore creating stabilization throughout the entire foot. These muscles are organized into four layers on the plantar aspect of the foot.4,6,9 Although there are multiple layers of intrinsic muscles at different depths on the 
plantar aspect of the foot, all four layers of intrinsic muscles are important to the complete aspect of the foot.10 Specific intrinsic muscles can be activated during individual exercises. Therefore, each intrinsic muscle may provide the benefits and properties of the plantar intrinsic muscles individually, depending on the movement of the foot and toes.10 The abductor hallucis muscle on the plantar aspect of the foot is commonly seen to be the most influential intrinsic muscle when it comes to intrinsic foot muscle strengthening, and foot or ankle injuries.4

One of the primary functions of the intrinsic muscles of the foot is control of the medial longitudinal arch (MLA). This structure is often known for stability, energy storage and release during gait phases, and raising the center of mass through recoiling and release.5,7,11 It is crucial to have a stable base for all activities, and the intrinsic muscles are the main source of that base stability. These intrinsic plantar muscles control arch deformation velocity and degree and allow more stability by activating the MLA.4,11 Intrinsic muscles play a large role in sensory information due to the stretch response for foot posture. The locations and actions of these muscles help with gait patterns, support of the arches, activities, and load placed on structures. 4 In order to provide this base of stability it is important to understand how to activate the intrinsic muscles of the foot. McKeon et al.4 reported that short foot exercises may be one form of exercise that strengthens those intrinsic muscles. Short foot exercise efficiently activates the abductor hallucis, helping to prevent the excessive pronation motion of the foot by lifting the MLA.7,11 With the activation of these plantar intrinsic foot muscles, improvements in dynamic alignment, control of arch positioning and balance abilities will be present.4,7 The short foot exercise targets the intrinsic muscles of the foot and enables more stabilization through the MLA, a reduction in excessive foot pronation and foot disability, and an increase in plantar force dispersion at the midfoot by neuromuscular control during weight bearing activities. 7,11 
The sport of ice hockey is often overlooked when it comes to balance or foot posture. However, due to the demands of the sport and the skate the athletes wear, ice hockey requires immense biomechanical facets, specifically stability due to the fast and dynamic demands of the sport. The skate that is utilized during ice hockey creates a narrow base of support for the athlete, thus increasing the demand for eccentric muscle control and proprioception for balance.12 With this constant demand, fatigue develops within the intrinsic foot muscles from overwork and stress due to the constant need for stability.12 As greater levels of power and efficiency are needed while on the lateral edge of the skate, 12 when an ice hockey player falls into pronation or has weak and fatigued plantar intrinsic muscles, performance levels will decrease.12 Although an ice hockey athlete's foot is within an ice skate, the foot is still needed to perform specific responsibilities such as force dispersion. By dispersing the forces from the mid foot through utilization of plantar pressure, plantar force is applied.13

There is extensive literature on intrinsic foot muscles as well as the benefits of intrinsic foot muscle activation. Through strengthening of the intrinsic muscles of the foot, increases in balance, foot posture and stability will occur.7,11 Although it is found that ice hockey athletes require extreme amounts of stability, the literature is lacking on the impacts of intrinsic foot muscles on ice hockey performance. Through activation of the intrinsic muscles, ice hockey players may demonstrate an increase in performance due to providing a decrease in foot pronation, an increase in MLA stability, an increase in neuromuscular control as well as an increase in plantar force dispersion at the mid foot. These aspects would allow ice hockey players to stay on the lateral edge of the skate, which has demonstrated an increase in agility and performance. 7,11,12Techniques of how to improve intrinsic muscle strength has not been evaluated in ice hockey players, nor has there been a comparison between a traditional 
strengthening program and a foot core program. Thus, the purpose of this study was to explore the effects of foot intrinsic muscle strengthening versus a traditional extrinsic muscle strengthening program on ice hockey players balance, foot posture, agility and perceived ability.

\section{METHODS}

Design

This study is a prospective repeated measures design determining the effects of intrinsic foot muscle strengthening on agility, perceived ability, balance and arch height in ice hockey players. The dependent variables consisted of navicular drop test, the star excursion balance test, the composite score on the FAAM for ADL and sport disability, and the S-cornering agility ice skating drill. The star excursion balance test consisted of anterior, posteromedial and posterolateral reach distances. The dependent variables included arch height, normalized reach distance, FAAM scores for ADL and sport, and time. The independent variables were tested on two levels (pre and post) and two groups were established for this 4-week study; a foot core strengthening group and a traditional foot rehabilitation methods group.

Subjects

This study included members of a mid-Atlantic university club D1 and D2 men's ice hockey teams. Approximately twenty-eight subjects were recruited (Age=19.96 \pm 1.59 yrs.; height $=180.56 \pm 6.70 \mathrm{~cm}$; mass $=79.04 \pm 9.06 \mathrm{~kg}$ ). All subjects were male and were between the ages of eighteen and twenty-four. Inclusion criteria included subjects who were healthy, currently on the roster for the men's club ice hockey team, no history of a serious injury to the ankle or foot in the past six months, no history of surgeries to the lower extremity within the last 6 months, and had no disorders or on medication that could affect the ability to perform any of the tests within this study. Exclusion criteria included a history of surgery to the lower extremity 
within the last 6 months, history of a serious injury to the lower extremity (i.e. fracture) within the last 6 months, and those who had a disorder that may affect ability to perform any of the procedures within the study. This study was approved by the Institutions Office of Research Compliance and Integrity.

Instruments

Foot and Ankle Ability Measure (FAAM) Questionnaire: The FAAM questionnaire allows for subjective measures to be taken in regard to the foot, ankle and lower leg. The ADL section of the FAAM consisted of 21-items while there were 8-items in the sports section.14,15 The ADL section related to the subject's ability to perform activities of daily living. The sports section portrayed to the subjects perceived disability associated with physical activity.14 The FAAM ADL and FAAM sport are self-report questionnaires that allow for assessment of physical function.14,15 This subjective measurement of the athlete's perceived function included activities of daily living as well as sport function.14,15

This self-reported subjective measurement through the FAAM allows for content validity, construct validity, score stability, reliability and responsiveness for athletes with musculoskeletal injuries of the lower extremity.14,15 The test retest reliability for the FAAM questionnaire consists of .89 and .87 for the ADL and sport sections, respectively.15 Both sections of ADL and sport were responsive for changes in status with a significance score of less than .05 .15 The ADL and sport sections also demonstrate a minimal detectable change through a 95 percent confidence interval of \pm 5.7 and \pm 12.3 points, respectively. 15

Navicular drop test: The navicular drop test was utilized to determine the height of the navicular tuberosity, which is often correlated with medial longitudinal arch (MLA) height as well as intrinsic foot muscle strength.2,7,16,17 The navicular drop test is a reliable test in 
determining the foot posture of the subject being measured, specifically looking at pronation of the foot or a drop in MLA height.2,7,16,17 According to Zuil-Escobar et al.,18 the navicular drop test is reproducible, reliable, valid and simple for evaluating MLA and navicular height. The navicular drop test demonstrates an intra- and inter-day repeatability of $1.1 \mathrm{~mm}$ and $2.3 \mathrm{~mm}$, which also correlates to intercorrelation coefficients of .97 and .87 .19 This test also demonstrated fewer disadvantages when compared to some other foot posture tests, such as footprint parameters. 18

Star Excursion Balance Test (SEBT): In order to evaluate balance, in particular dynamic postural control, the star excursion balance test (SEBT), or "Y" balance test, was utilized.2,7,16,20,21 The SEBT can be performed in the directions of anterior (A), anterolateral (AL), anteromedial (AM), medial (M), posteromedial (PM), posterior (P), posterolateral (PL), and lateral (L).2,7,16,20,21 The three directions utilized for this study included anterior (A), posteromedial (PM), posterior lateral (PL).2,7,16,20,21 The SEBT is a reliable method of measuring balance and the three directions of anterior, posteromedial and posterolateral were utilized to assess specific aspects of dynamic postural control.22

The SEBT is a reliable measurement tool for dynamic balance and postural control.2,7,16,20,21 Specifically related to ankle instability patients, the SEBT has a high rate of reliability in detection of reach deficits.22 Kinzeyet al.23 found an intraclass correlation coefficient (ICC) of .86 to .98 , demonstrating moderate reliability for the SEBT in assessing dynamic balance, while Lynn et al.16 found an ICC of .67 to .87 demonstrating good reliability of the "Y" balance test, or SEBT. Mulligan and Cook7 found that the SEBT had an ICC of .87 for anterior reach, .87 for posteromedial reach, and .86 for posterolateral reach demonstrating good reliability for all directions. The SEBT demonstrates excellent inter and intra-rater reliability, 
minimal detectable change, associations with increase injury risk, and convergent validity. 24-26 This dynamic balance test is shown to be a reliable and valid test that examines postural stability.27 The SEBT primarily incorporates dynamic balance, but the incorporation of coordination, strength, proprioception, and power are also demonstrated through multiple lower extremity and trunk movements.21

S-Cornering Agility Test: In order to evaluate on-ice agility for ice hockey players, the SCornering agility test was utilized. This agility test is performed on the ice and requires the athlete to skate in the shape of an "S" at full potential speed.28 This specific agility test requires acceleration, deceleration, balance, cross over skating patterns, as well as other skating components. The S-Cornering agility test has demonstrated good reliability with an ICC of .76 with a p value of $<.01 .28$ This can be utilized on a variety of skill levels for ice hockey athletes to determine agility performance. 28

Procedures

Subjects were contacted and instructed to attend a meeting at the ice rink where an Informed Consent Form (Table C1) as well as a self-report injury history questionnaire (Table C2) were completed. At the meeting in the ice rink the subjects were given a description of the study in order to make an informed decision about participating in the study. If any of the subjects had questions regarding the study, they were answered in full detail. After a description of the study was given and any questions were answered, those that volunteered to be in the study then completed the informed consent form and self-report injury history questionnaire. These forms were filled out truthfully and to the best of the subject's ability. The self-report injury questionnaire assisted in inclusion and exclusion criteria of the study by addressing if any of the subjects have had serious ankle or foot injuries in the past six months as well as any 
surgeries to the lower extremities. The researcher then reviewed all the forms to ensure the athlete met the inclusion criteria, and not the exclusion criteria. If inclusion criteria were met by the subjects, they were then contacted by the researcher to complete pre-tests for the FAAM ADL and FAAM Sport questionnaire (Table C3), the navicular drop test (Table C4), the three directions of the SEBT (Table C5), and the S-Cornering agility drill (Table C6). Upon completion of the study, the subject completed the post-tests following the exact specifications as the pre-tests.

Pre-Post testing

FAAM ADL and FAAM Sport: The subjects in the study completed the FAAM ADL and FAAM Sport sections. The subjects were asked to answer the 21 -item questionnaire of the FAAM ADL section and the 8-item questionnaire of the FAAM Sport section. The rating was based on a scale from no difficulty, slight difficulty, moderate difficulty, extreme difficulty and unable to do.14,15 The FAAM ADL required a single response for each question that accurately demonstrates the condition within the past week. An answer of not applicable (N/A) was applied to the activities that are limited by something other than the foot and ankle. The athlete was then asked to rate the perceived functional ability during ADL's on a scale of 0-100 percent. The FAAM Sport section utilizes a single response to questions regarding the condition within the past week as well. Once again, activities that are limited by something other than the foot and ankle were answered by not applicable (N/A). The subject was then asked to rate the perceived functional ability during sports activities on a scale of 0-100 percent.14,15

Navicular drop test: The navicular drop test was initiated while the patient was sitting in a chair with hips and knees at 90 degrees of flexion. The subjects' foot was placed into subtalar neutral by the researcher. This was performed by palpation of the head of the talus while the 
subject moved the foot into pronation and supination. When the talar head depth was palpable on both sides, the foot was in subtalar neutral.2,7,16,17 The researcher then palpated the subjects' foot for the navicular tuberosity. A mark was placed over the navicular tuberosity and, with the use of an index card, the distance from the floor to the marked navicular tuberosity was marked on the index card. This demonstrated the subjects foot posture during non-weightbearing activities.2,7,16,17 After that measurement was obtained, the subject then stood up from the chair. The measurement was performed again from the floor to the marked navicular tuberosity, once again marked on the same index card. This demonstrated the subjects foot posture during weightbearing activities. 2,7,16,17 The difference between the seated measurement mark and the standing measurement mark on the index card was measured with the use of a tape measure, representing the subjects' navicular drop or arch height.

Star excursion balance test (SEBT): True leg length was measured for each subject within the study by measuring from the anterior superior iliac spine (ASIS) to the medial malleolus. This was performed and recorded to normalize the data to true leg length for each subject.2,7,16,2022 The SEBT was performed with a "Y" placed on the floor with white athletic tape. The subjects stood in the middle of the "Y" and were asked to reach in the directions of anterior (A), posteromedial (PM) and posterolateral (PL).2,7,16,20,21 The subject, while in a single leg stance, made a light touch on the line, and avoided transfer of weight when the reach leg was returned back to the middle of the "Y".

The anterior direction consisted of the subject reaching in front as far as able while maintaining position and posture of the test.22 The posteromedial direction consisted of the subject reaching behind and in the same direction as the reach leg, while the posterolateral direction consisted of the subject reaching behind the stance leg.2,7,16,20,21 The subject was 
allowed three practice trials for each direction. After a five-minute rest interval, the subjects performed three trials of each of the three reach directions in a randomized order. Index cards were labeled for each of the three directions and were selected by the subjects to determine which direction to start with and for each subsequent direction. The reach distance was determined by measurement from the mark on the tape to the center of the "Y"..22 The trial was excluded and repeated if the researcher believed the subject used the reach leg for support at any time, removed the foot from the center of the "Y" or was unable to maintain balance throughout the trial.2,7,16,20,21

Ice hockey S-cornering agility drill: The subject was stationed on the ice behind one of the goals. The time was not started until the first movement. The subject began by skating around the first face-off circle. They then proceeded to cross-over skate around the other face-off circle within the same zone. 28 The subject finished at the first blue line. The time was stopped once the first skate crossed the blue line. Throughout this agility test the subject skated a half figure 8 pattern around the face off dots in a crossover pattern. If the subject tripped or fell, he was able to restart the agility drill. Time was determined through a stopwatch on a cellular device.28 Foot Core Interventions

The short foot exercise (Table C7) consisted of the subjects seated with the hips and knees in 90 degrees of flexion. The subject was taught to sense when the foot was in the subtalar neutral position. By moving the foot into supination and pronation and feeling when the calcaneus and metatarsals are equally placed on the ground, subtalar neutral was found.4,10,29 Once the foot was positioned in subtalar neutral, the subject was then instructed to create a dome with the foot by raising the arch. This was performed by drawing the metatarsal heads toward the calcaneus without flexing the toes or incorporating extrinsic leg muscles.4,10,29 The subject held 
this position for ten seconds and then relaxed. The contraction was completed five times for three sets.

While the subject was performing this intervention, the researcher was examining the subjects form and technique for a drop in the navicular position as well as any activation of extrinsic leg muscles. If either of these were noticed, the subject was instructed to reset into subtalar positioning and start the exercises again.4,10,29 This exercise was performed through a progression throughout the 4-week study. The first week the subject remained seated, the second week progressed to performing this exercise while standing, the third week progressed to single limb stance while holding on the a table for support and finally the fourth week a single limb stance with no support was performed.4,10,29 The subject was only allowed to progress if proper form and technique were demonstrated throughout. The subjects performed all stages of this exercise bilaterally without any problems.4,10,29

The toes-spread-out exercise (Table C7) consisted of the subjects also positioned seated with the hips and knees flexed to 90 degrees. The subject had feet placed flat on the floor. The subjects were then instructed to extend all five toes off the ground and then instructed to abduct those five toes.10 While the toes were in an extended and abducted position, the subjects were instructed to flex only the first and fifth toes back down to the floor, while keeping the second through fourth toes extended. This exercise was performed through a progression throughout the 4-week study. The first week the subject was instructed to just extend and abduct all toes, the second week progressed to extension and abduction of all toes with flexion of only the first toe down to the floor, and finally the third and fourth weeks were extension and abduction with both the fifth and first toes flexed to the floor.10 The subject was only allowed to progress if proper form and technique were demonstrated throughout. The subjects performed all stages of this 
exercise bilaterally and simultaneously without any problems.10 This exercise was performed ten times for three sets at each stage. 10

Traditional Exercise Intervention

The towel curl exercise (Table C8) consisted of the subject in a seated position with the hips and knees at 90 degrees of flexion. A towel was placed under the subject's foot. The subject was on a slick surface of tile, so that the towel could easily glide on the floor.4,7,16,17 The subject was instructed to drag the towel under the foot by only flexing the toes. As the towel was being gripped and pulled, the subject was instructed to hold that grip with the toes for a total of three seconds for each grip. This exercise was considered completed when the subject dragged the entire towel for a total of three times. The subject was instructed to restart this exercise if it was noticed that the entire lower leg was being used to drag the towel, instead of just solely using the flexion of the toes.4,7,16,17 This exercise was performed bilaterally alternating limbs.

The foam pick up exercise (Table C8) was also performed as the subject was seated with the hips and knees in 90 degrees of flexion. The researcher cut a large piece of foam into thirty pieces of different shapes and sizes. These pieces of foam were then scattered on the floor surrounding the seated subject. The subject was instructed to pick up each piece of foam individually by gripping the piece of foam with the toes through toe flexion. They then placed the piece of gripped foam into a container that was placed by the seated subject. This exercise required the subject to pick up every piece of foam individually for a total of three sets. The subject was instructed to restart the exercise if multiple pieces of foam were picked up at one time. This exercise was performed bilaterally and simultaneously, alternating feet by picking up fifteen pieces of foam with each foot.

Data Analysis 
Data for the SEBT was analyzed by the mean and normalized by leg length. The means of reach distance from the 3 trials of each performance of the SEBT were calculated and used for statistical analysis. Reach distances was then divided by the measured leg length and multiplied by 100 to calculate a dependent variable that represents reach distance as a percentage of leg length.2,7,16,20-22 Data for the navicular drop test was utilized by taking the marked height in centimeters of the seated position and the marked height in centimeters of the standing position on the index card and measuring the distance between them. This then provided the height of the navicular drop or arch height difference from non-weight bearing to weight bearing.2,7,16,17 A smaller number represented a positive foot posture and limited foot pronation of the subject when transferring into weight bearing activities. A larger number demonstrated a negative foot posture and a greater percentage of foot pronation occurring when transferring to weightbearing activities for the subject.2,7,16,17 Performance for the ice hockey S-Cornering agility drill was determined by the time for each subject. A shorter time demonstrated increases in agility and ice hockey performance, while higher times demonstrated decreases in agility and ice hockey performance. 28

Statistical Analysis

Statistical analyses included means and standard deviations. Two separate $2 \times 2 \times 2$ repeated measures ANOVA (time $\mathrm{x}$ group $\mathrm{x}$ limb) were used for the FAAM ADL section and the FAAM Sport section. Three separate $2 \times 2 \times 2$ repeated measures ANOVA (time $\mathrm{x}$ group $\mathrm{x}$ limb) were used for the SEBT, one for each direction performed by the subjects. One $2 \times 2 \times 2$ repeated measures ANOVA (time $\mathrm{x}$ group $\mathrm{x}$ limb) were used for navicular drop. One 2x2 repeated measures ANOVA (time $\mathrm{x}$ group) was utilized for the S-Cornering agility drill. Alpha level utilized a priori of $\mathrm{P}=0.05$ for all analyses. The strength of the effect sizes was determined as 
small $(<0.4)$, moderate $(0.41-0.71)$, and large effects $(>0.71) .22$ IBM SPSS software

(IBM/SPSS Inc., Chicago, IL) version 26.0 was used for all analyses.

\section{RESULTS}

Twenty-six of the twenty-eight randomized participants completed the entire study as allocated and were not harmed in the process. One participant was excluded due to having mononucleosis at the time of pre-testing and another participant decided to drop-out of the study due to school and class obligations. Descriptive statistics and effect size for the pre-test and posttest data by group including Foot and Ankle Ability Measure (FAAM) ADL and Sport sections, foot posture through navicular drop, balance through the SEBT, and agility through the Scornering drill. This information can be found in Table D1 for FAAM and Table D2 for navicular drop, SEBT and agility. The groups were similar at baseline for all dependent variables for FAAM, navicular drop, SEBT and agility.

Patient-Oriented Outcomes

For the FAAM ADL and Sport sections, there were no interactions demonstrated for the right or left limb. There were also no main effects for group, time or limb observed. Both groups, foot core and traditional, showed no differences for the ADL and Sport sections of the FAAM. The left limb for both groups demonstrated no statistically significant changes for the Sport section $($ foot core pretest $=100 \pm 0$, posttest $=99.79 \pm .80$; traditional pretest $=98.17 \pm 4.78$, posttest $=98.42 \pm 5.48)$ and ADL section (foot core pretest $=99.79 \pm .58$, posttest $=99.71 \pm 1.07$; traditional pretest $=98.67 \pm 3.23$, posttest $=99 \pm 3.46$ ). The right limb for both groups demonstrated no statistically significant changes for the Sport section (foot core pretest $=99.14 \pm 3.21$, posttest= 99.79 \pm .80 ; traditional pretest $=98.17 \pm 4.78$, posttest $=98.42 \pm 5.48)$ and ADL section $($ foot core pretest $=99.36 \pm 1.65$, posttest $=99.5 \pm 1.61 ;$ traditional pretest $=98.67 \pm 3.23$, posttest $=$ 
98.67 \pm 3.55$)$. Small effect sizes were shown for the right and left limb for FAAM ADL and Sport.

Clinically Oriented Outcomes

Navicular Drop

Both the foot core and traditional groups showed significant differences for navicular drop in both the right and left limb. There was a significant difference between pre-post tests for both of the groups for right navicular drop (pretest foot core $=6.43 \pm 3.84$, posttest foot core $=$ $4.71 \pm 1.89 ; \mathrm{p}<.001$, pretest traditional $=7.75 \pm 2.49$, posttest traditional $=5.25 \pm 2.22 ; \mathrm{p}<.001)$ and left navicular drop (pretest foot core $=7.29 \pm 3.05$, posttest foot core $=4.04 \pm 2.73 ; \mathrm{p}<.001$, pretest traditional $=8.5 \pm 2.65$, posttest traditional $=6.25 \pm 2.14 ; \mathrm{p}<.001)$. The right and left limbs of each group demonstrated a decrease in navicular drop after the traditional and foot core exercises were performed for the four-week trial period. A moderate effect size was shown for the right limb of the traditional group while a large effect size was shown for the left limb of the traditional group and the right and left limbs of the foot core group.

SEBT

There was a significant limb main effect for both groups and a significant test by group interaction for right $\mathrm{A}$ (foot core pretest $=73.97 \pm 11.31$, posttest $=71.42 \pm 8.91$; traditional pretest $=67.44 \pm 8.89$, posttest $=71.05 \pm 7.27 ; \mathrm{P}=.032, \mathrm{P}=.024)$ and left $\mathrm{A}$ (foot core pretest $=75.13 \pm 8.7$, posttest $=74.18 \pm 6.33$; traditional pretest $=67.6 \pm 7.26$, posttest $=72.27 \pm 7.22 ; \mathrm{P}=.032, \mathrm{P}=.024)$. There was a significant test main effect for both groups and a significant limb by test interaction for right $\mathrm{PM}$ (foot core pretest $=96.17 \pm 11.82$, posttest $=100.89 \pm 11.41$; traditional pretest $=$ 87.42 \pm 10.05 , posttest $=93.38 \pm 9.69 ; \mathrm{P}<.001, \mathrm{P}=.031)$ and left $\mathrm{PM}($ foot core pretest $=$ $93.73 \pm 12.39$, posttest $=100.66 \pm 11.84$; traditional pretest $=86.37 \pm 10.62$, posttest $=95.89 \pm 9.19$; 
$\mathrm{P}<.001, \mathrm{P}=.031$ ). There was a significant test main effect for both groups for right $\mathrm{PL}$ (foot core pretest $=77.65 \pm 7.89$, post-test $=83.60 \pm 8.93$; traditional pretest $=74.60 \pm 12.46$, posttest $=$ $79.81 \pm 10.71 ; \mathrm{P}=.001$ ), and left PL (foot core pretest $=75.75 \pm 8.16$, post-test $=85.12 \pm 9.94$; traditional pretest $=76.71 \pm 10.52$, posttest $=84.52 \pm 11.16 ; \mathrm{P}=.001)$. The anterior direction demonstrated an increase in reach distance for the traditional group with a moderate effect size for the right and left limbs for the traditional groups and a small effect size for the right and left limbs for the foot core groups. The posteromedial direction demonstrated an increase in reach distance for both groups and both limbs with a moderate effect size for right limb of the traditional groups and left limb of the foot core group and a small effect size of the left limb of the traditional group and right limb of the foot core group. The posterolateral direction demonstrated an increase in reach distance for both groups and both limbs with a large effect size for both limbs of the foot core group and the left limb of the traditional group and a moderate effect size of the right limb of the traditional group.

Agility

There was a significant test main effect for both groups for the S-cornering agility test $($ foot core pretest $=8.97 \pm .78$, posttest $=8.51 \pm .96 ;$ traditional pretest $=9.01 \pm 1.12$, posttest $=$ $8.41 \pm 1.16 ; \mathrm{P}<.001)$. Both the traditional and foot core groups showed faster times with the on-ice agility measure through the S-cornering agility test after the traditional and foot core exercises were performed. A moderate effect size was demonstrated for both the foot core and traditional groups in this study.

\section{DISCUSSION}

The purpose of this study was to explore the effects of foot intrinsic muscle strengthening versus a traditional extrinsic muscle strengthening program on ice hockey players balance, foot 
posture, agility and perceived ability. The primary findings indicated an improvement in both the foot core exercise group and the traditional method in navicular drop, balance and agility. Within this study, there were no significant differences between groups for clinically oriented outcomes or patient-oriented outcomes. Significant differences were not shown for either group for patientoriented outcomes in FAAM ADL and Sport. However, significant differences were shown for both groups within the clinically reported outcomes of navicular drop, balance and agility. Navicular drop showed a significant difference for test with both limbs. The SEBT showed significant difference in the anterior direction for test by group and limb, in the posteromedial direction for test by group and test, as well as in the posterolateral direction for test. Agility showed a significant difference for test. The groups were similar at baseline for all dependent variables for FAAM, navicular drop, SEBT and agility.

Within a brief treatment period of four weeks, the foot core and traditional groups improved pre-to-post intervention but neither group performed any better than the other statistically. However, effect sizes from pre-to-post intervention, small, moderate and large effect sizes were evident with most variables for FAAM-ADL, FAAM-Sport, navicular drop, SEBT and agility in relation to pre-test/post-test following the respective exercise programs. It appears that subjects were trending toward clinically meaningful change with these interventions, thus providing some clinical relevance. During a four-week time period, changes were becoming evident for clinically oriented outcomes. As this is the first study to compare foot core exercises to traditional exercises for ice hockey athletes, it is difficult to draw direct conclusions with comparisons to other known studies in this area. Foot and Ankle Ability Measures Questionnaire 
This self-reported subjective measurement was utilized to determine the subjects perceived ability and function throughout ADL's and Sport activities. 14,15 For the FAAM questionnaire it was hypothesized that the foot core exercise group would demonstrate increases in perceived ability on the sport specific section of the FAAM questionnaire pre-to-posttest when compared to the traditional rehabilitation group after a 4-week intervention. It was also hypothesized that the foot core exercise group would demonstrate minimal increases in perceived ability on the activities of daily living section of the FAAM questionnaire pre-to-posttest when compared to the traditional rehabilitation group after a 4-week intervention. Both of these hypotheses were rejected at the completion of this study.

In this study there were no significant changes of the FAAM ADL or Sport sections. This includes no differences pre-to-post intervention between left and right limb, between groups and between pre and post testing. All effect sizes regarding the FAAM, ADL and Sport sections, were small, showing no clinically relevant changes within this study. Ice hockey athletes do not typically experience many foot or ankle injuries due to the demands of the sport. Intrinsic muscle fatigue can become common due to the biomechanical requirements of ice hockey and traumatic acute injuries can also become common due to the intensity and high contact of the sport.12 However, of podiatric pathologies, hammertoes and bunions are among the most common that occur in ice hockey due to the friction and pressure caused by the ice hockey skate.12 Lower extremity pathologies can become more prominent such as groin or back injuries from the overuse aspect of the sport.12 However, within this specific study's population, no serious lower extremity injuries occurred within the past 6 months, making them an overall healthy population with normal lower extremity function. 
One reason for no significant change within the FAAM could be due to the subjects being healthy before the study began, creating a high score on both FAAM sections to begin with since a certain score was not needed to be included in this study. Carcia et al.14 studied the validity of the FAAM ADL and Sport on athletes with chronic ankle instability. This study demonstrated that the athletes within the study that were healthy, or reported that foot and ankles were normal, scored higher on both the ADL and Sport sections of the FAAM when compared to the athletes with chronic ankle instability, or athletes that reported ankles were nearly normal or abnormal. Therefore, chronic ankle instability demonstrated significant impact on the FAAM scores for both ADL and Sport sections within Carcia et al.'s14 study. The findings within Carcia et al.14 can be implemented with the findings of this study due to all participants within this study being healthy and having no injuries or problems with the foot or ankle throughout the entirety of the study. Therefore, since the population utilized within this study were healthy and not experiencing any lower extremity injuries or chronic ankle instability, the results for the FAAM ADL and Sport sections were not significant. The FAAM ADL and Sport sections are reliable and valid measures of physical function and perceived function, however it is important to understand that the population within this study were not experiencing any type of disorders or injuries of the lower leg, foot or ankle and, therefore, the FAAM tool was not significant to the findings of this study.14,15 It is possible that the interventions examined in the current study would have shown improvements in FAAM scores for ADL and Sport in individuals that report lower FAAM scores prior to the intervention.

Patient-reported outcomes are useful for measuring what is important to patients and for evaluating patient outcomes. Changes in patient-reported outcomes should be used as only one of many factors in measuring improvements after a rehabilitation protocol. Some improvement may 
represent a subtle change in the participant's abilities; therefore, even if a change does not reach the level of the MDC, it may still be an important milestone to document when making progression decisions. The FAAM ADL subscale scores showed small improvements for the left limb (.08 to .33) and right limb (0 to .14) in both groups after the 4-week intervention period. These limited improvements may be attributed to the higher level of function of participants at baseline. This was also similar for the FAAM Sport subscale scores for the left limb (-.21 to .25) and right limb (.25 to .65) of both groups. Further, as the FAAM ADL and the Sport subscale are region specific for the foot and ankle, it may be difficult to tease out foot function alone. Future studies should determine a self-reported regional foot specific questionnaire that can address foot structure and foot posture in relation to balance and mobility.

Navicular Drop

This test was utilized to measure foot posture, navicular tuberosity height and intrinsic muscle strength. 2,7,16,17 The experimental hypothesis for navicular drop was that the foot core exercise group would show a decrease in navicular drop pre-to-posttest after a 4-week intervention (i.e. a decrease in foot pronation). This was accepted as this study presented significant decreases in navicular drop measurements, looking at pre-to-post testing where both the foot core and traditional exercise groups decreased navicular drop with an average of 2.08 $\mathrm{mm}$ for the right foot and $2.77 \mathrm{~mm}$ for the left.

However, the significant decreases in navicular drop were not influenced by which group the subjects were in, both groups demonstrated a significant improvements in navicular drop measurements. This is consistent with the study by Lynn et al.16 which included 24 healthy subjects performing either towel curl exercises, short foot exercises or no exercises at all and observed no difference between the towel curl and short foot groups with navicular drop. Both 
groups showed improvements in navicular drop in the nondominant stance leg. 16 The study by Mulligan and Cook7 observed a healthy population of 3 male and 18 female subjects performing only the short foot exercise and an improvement in navicular drop was demonstrated. Within this study benefits for arch height were evident for foot core related exercises, which is consistent with the findings of this study.7 Lynn et al.16 demonstrated how towel curls can have the same impact on navicular drop as short foot exercises, while McKeon et al.4 and Okamura et al.29 demonstrated a positive impact through foot core exercises on navicular drop. These findings can be related to the results of this study with both groups improving in navicular drop. Therefore, both intrinsic and extrinsic muscle strengthening allows for support of the MLA and a decrease in foot pronation.4,16,29

Although both groups demonstrated significant decrease for navicular drop, it is important to understand that specific change. Within this study the subjects' feet were placed in a neutral position, or subtalar neutral, upon testing. During the pre-testing of navicular drop, ten of the twenty-six subjects demonstrated more pronated feet in the weight bearing position presenting with navicular drop measurements of $10 \mathrm{~mm}$ or greater for either or both feet. During the post-testing of navicular drop, only one of the twenty-six participants demonstrated a measurement of $10 \mathrm{~mm}$ or greater for either or both feet. Mulligan and Cook 7 reported that a measurement of greater than $10 \mathrm{~mm}$ is an abnormal range for navicular drop, therefore, after the exercises were performed for 4-weeks, almost all subjects demonstrated a more neutral position of the foot in weight bearing. Mulligan and Cook7 also reported that a measurement of 6-9 $\mathrm{mm}$ is a normal range for navicular drop measurements. Within this study it was also demonstrated that eleven subjects presented with navicular drop measurements lower than $6 \mathrm{~mm}$ at pre-testing for either or both feet. At post-testing nineteen subjects presented with measurements of below 6 
$\mathrm{mm}$ for either or both feet, demonstrating that after the exercises were performed for 4-weeks eight subjects went from normal ranges of navicular drop to above average or excellent measurements.7

There were also differences in the improvements of navicular drop measures where the left limb showed a greater decrease within the navicular drop measurements for the foot core group by $1.5 \mathrm{~mm}$, while the traditional exercise group demonstrated a minimally greater decrease in the right foot by $.25 \mathrm{~mm}$. Although both demonstrated a change based on limb, the traditional exercise groups greater decreases in the right limb seems to be more of a measurement error than a clinically significant difference. The reason for one limb demonstrating a greater decrease is not completely known, but it could be due to the biomechanics of skating or preferred limb for the exercises performed. Humble et al.12 reported that as an ice hockey player is skating, the center of gravity is not positioned the same as with normal walking patterns due to the low friction surface of ice creating a decrease in posterior linear forces. Through lower friction levels, the ice hockey athletes are required to place the foot in abduction and the hip in external rotation during the propulsive stages of skating.12 The decrease in these forces and direction of movement at the foot and hip make the center of gravity move in the opposite direction of the limb that is weight bearing. 12 Therefore, if the subjects were predominantly right footed and preferred to push off with the right foot or weight bear on the right foot more than the left, the right foot would be placed in a more pronated position more often than the left. This could explain why the left foot demonstrated a greater decrease for the foot core group, since the right foot would be placed into pronation more often than the left, creating a greater navicular drop position, weaker intrinsic muscles and making it more difficult to decrease that navicular drop height. 12 Within future studies it may be helpful to record the dominant limb of each subject to determine if this is 
true. The differences in limb measurements could also be due to the exercises being performed and which foot was easier to perform those specific exercises. If the exercises were easier to perform on one limb rather than the other, then the muscles would work more efficiently and therefore become stronger in that specific foot. When the intrinsic and extrinsic muscles become stronger the navicular bone and the MLA become more supported and navicular drop will then decrease $.5,7$ However, the important aspect of this study is that there was an improvement for both groups for navicular drop.

Both groups within this study, demonstrated significant improvements in navicular drop, resulting in a decrease in foot pronation, or arch collapse, and corrected foot alignment by utilization of both foot core and traditional exercises. Even though both interventions were of a four-week duration, it appears that the subjects are starting to trend in the right direction to reach clinically meaningful change. The improvements from pre-to-post intervention and the small, moderate and large effect sizes show clinically relevant changes over the course of four weeks within the two groups. Understanding completely why these changes occurred may be difficult as this is the first study utilizing the ice hockey population rather than cross country or track and field athletes10 or chronic ankle instability patients.

Star Excursion Balance Test

The SEBT was utilized to determine dynamic postural control of the subjects and how it was impacted by foot core and traditional exercises. The SEBT allowed for measurement of dynamic balance as well as incorporation of coordination, strength, proprioception and power. 2,7,16,20,21 The experimental hypothesis for the SEBT was that an increase in distance in posteromedial and posterolateral on the SEBT would be observed from the foot core exercise group after a 4-week intervention. This was accepted since both the foot core group and 
traditional exercise group improved in these two directions. This study incorporated the three directions of anterior, posteromedial and posterolateral. Within the anterior direction, a significant change was demonstrated for limb and test by group with an average increase in reach distance of $1.64 \mathrm{~cm}$ for the left limb and $.29 \mathrm{~cm}$ for the right limb. Within the foot core group, the anterior direction showed a decrease in reach distance of $-.95 \mathrm{~cm}$ for the left limb and -2.55 $\mathrm{cm}$ for the right limb demonstrating that the foot core exercise group did not improve from preto-post testing. Within the traditional exercise group, increases of $4.67 \mathrm{~cm}$ for the left limb and $3.61 \mathrm{~cm}$ for the right limb in the anterior direction were presented. Therefore, within the anterior position of the SEBT, the traditional group improved with increases in reach distance while the foot core group decreased in reach distance. This is consistent with Mulligan and Cook's study which examined 21 healthy participants performing short foot exercises and found that the participants improved in all directions of the SEBT tested (anteromedial, medial, posteromedial and posterior) except for in the anterior direction. Within the rigid ice hockey boot there is typically a heel lift of five to nine degrees, putting the foot in a plantarflexed position. Therefore, ice hockey players may be limited in dorsiflexion through ankle joint restriction creating decreases in the anterior direction of the SEBT.12 The greater increase within the traditional exercise group in the anterior direction could be due to the towel curl and foam pick up exercises requiring activation of extrinsic muscles, such as the posterior tibialis, anterior tibialis and fibularis muscles, in addition to intrinsic muscles. This then created enhancements in subtalar joint control through greater increases in extrinsic muscle control and total awareness. 7 Although the toes-spread-out exercise involves activation of the toe extensor muscles, Gooding et al.10 demonstrated that this specific exercise mainly targets the abductor digiti minimi, adductor hallucis oblique, and flexor digiti minimi. Therefore, the extrinsic muscle activity within the 
traditional group could be the cause of the greater increase within the anterior direction of the SEBT, since the anterior direction requires more extrinsic muscle activation through greater dorsiflexion and knee flexion of the stance leg.

Within the posteromedial direction a significant change was demonstrated for test by limb and test with an average increase in reach distance of $8.13 \mathrm{~cm}$ for the left limb and $5.29 \mathrm{~cm}$ for the right limb. The posteromedial direction showed a significant improvement for both the foot core and traditional exercise groups. Within the foot core group, increases of $6.93 \mathrm{~cm}$ for the left limb and $4.72 \mathrm{~cm}$ for the right limb were present while the traditional exercise group showed increases of $9.53 \mathrm{~cm}$ for the left limb and $5.96 \mathrm{~cm}$ for the right limb. This indicated that the left limb presented with greater improvements than the right limb in the posteromedial direction for both groups. These findings are similar to those with Lynn et al.,16 where 24 healthy subjects performed either towel curl exercises, short foot exercises or no exercises at all. Dynamic balance, static balance and navicular drop where all observed within this study. Lynn et al.16 demonstrated that dominant limb and non-dominant limb played a role in the dynamic balance test of the "Y" balance test, however the dependent variable measured was center of pressure (COP) movement. The short foot exercise group within Lynn et al.16 was able to decrease in COP movement within the non-dominant leg more so than the towel curl exercise group. This could also be related to this current study, as the left limb demonstrated greater reach distances for both groups. Therefore, if the right limb in both groups experienced a decrease COP movement, then the reach distances for the left limb could be increased through greater stability of the stance limb, or right limb, as COP is often related to performance for dynamic balance. 16 Another possibility for this change could be due to the demands of the sport of ice hockey, in particular balance requirements.12 If the subjects mainly prefer to balance on their right leg 
during skating, that could explain why the reach distances for the left limb were greater than the right limb since balance would be enhanced in the dominant balance leg on the ice further transferring to the stance leg of the balance test.12 Skating preferences and movement could impact which foot performed better on the SEBT in ice hockey players, as well as many other factors.

The posterolateral direction showed a significant change for test with an average increase in reach distance of $8.65 \mathrm{~cm}$ for the left limb and 5.61 for the right limb. Within the foot core group, increases of $9.37 \mathrm{~cm}$ for the left limb and $5.95 \mathrm{~cm}$ for the right limb were present while the traditional exercise group showed increases of $7.81 \mathrm{~cm}$ for the left limb and $5.21 \mathrm{~cm}$ for the right limb. Just as with the posteromedial direction, this demonstrated that the left limb presented with greater increases than the right limb in the posterolateral direction for both groups. This greater increase could be due to the COP movement within the right limb, preference or focus during the exercises on one limb over the other as well as the balance requirements within the sport of ice hockey as described for the posteromedial direction.12,16

The results from the SEBT concur with the article by McKeon et al.4 that discusses the foot core system and its potential benefits, showing increased balance ability and dynamic posture after a foot core exercise intervention. McKeon et al.4 explained that although both intrinsic and extrinsic muscle strengthening may benefit many deficits within subjects, the foot core exercise intervention typically showed a greater increase in dynamic control or balance when compared to traditional methods that incorporate extrinsic muscles. This is consistent with the findings of this study as the foot core exercise group demonstrated slightly greater reach distances in the posteromedial and posterolateral directions of the SEBT. This can also be related to the study by Mulligan and Cook7 where the participants, through the performance of short foot 
exercises, demonstrated an increase in reach distance in all directions of the SEBT (anteromedial, medial, posteromedial and posterior) aside from anterior. The directions of posteromedial and posterolateral can often be related to the sport of ice hockey, which may be a reason as to why those directions showed greater reach distances for the foot core group. While skating, the ice hockey athlete often performs the direction of posteromedial when pushing of into abduction as well as posterolateral when crossing over to turn or change direction. 12

Throughout utilization of foot core exercises and traditional exercises, both groups were able to demonstrate improvements in dynamic stability and balance through increasing reach distances on the SEBT. As stated by McKeon et al.4, intrinsic muscle strengthening is important in order to maintain stability of the MLA and foot. Further stated by Mulligan and Cook7, through strengthening of the extrinsic muscles, support of the MLA is enhanced as well as stability of the subtalar joint. Therefore, strengthening is a key component of enhancing balance and stability. Within this study, effect sizes fluctuated for all three directions, from small to moderate for anterior, moderate to large for posteromedial, and small to large for posterolateral. However, since all effect sizes crossed zero, the effects are null and void. Even though this study only consisted of a 4-week intervention period, both of the groups are showing movement in the correct direction in meeting clinically meaningful changes. In some cases, a main effect was demonstrated while in others there was an interaction for the dependent variables. This could be due to the specific interventions or due to the groups being similar at baseline and all healthy participants with limited ankle and foot injuries. Understanding completely why these changes occurred may be difficult as this is the first study utilizing the ice hockey population. Utilizing different populations with histories of ankle or foot injuries, or chronic ankle instability, may 
make it easier to understand changes due to the necessary stability that the exercises would provide to an injured population.

\section{S-Cornering Agility Test}

The S-Cornering agility test was utilized within this study to determine performance of the ice hockey athletes that participated in this study. The experimental hypothesis for agility was a demonstrated decrease in time on the S-cornering agility drill would be observed for those in the foot core exercise group pre-to-posttest after a 4-week intervention. This was accepted as the foot core group improved in agility by decreasing times on the S-Cornering Agility test. However, the traditional exercise group improved as well. Between both groups there was an average decrease of .53 seconds. The foot core group demonstrated a decrease of .46 seconds, from 8.97 seconds to 8.51 seconds, while the traditional group demonstrated a decrease of .6 seconds, from 9.01 seconds to 8.41 seconds. Therefore, both groups presented with improvements in agility post exercises due to addressing intrinsic and extrinsic muscle strength. This agility test was utilized in the past as a functional sport measure, demonstrating reliable results for agility functional measurements, but not related to interventions of the lower limbs.28

Within the study by Janot et al.28, the S-Cornering agility test was utilized, among other on-ice performance tests, as a timed on-ice agility measure for both male and female Division III collegiate ice hockey players. This study specifically examined if off-ice performance variables could predict on-ice performance for Division III collegiate ice hockey players through means and standard deviations of off-ice and on-ice variables. Within the on-ice variables, the SCornering agility test means and standard deviations for the men, the women and both genders combined were available. These data stated that the mean speed on the S-Cornering agility test for the men was 8.36 seconds. When comparing Janot et al.'s 28 results to the current study's 
data, it is shown that the subjects within this study demonstrated times closer to the times of Division III collegiate male ice hockey players during the post-testing after the exercises were performed.

Ice hockey athletes require balance and stability on a narrow base of support while skating in multiple directions.12 It has been demonstrated that an ice hockey athlete's performance is best when on the lateral edge of the skate. This allows for the athlete to enable an increase in power and efficiency by avoiding falling into foot pronation.12 Just as Humble et al.12 explained, when an ice hockey athlete has strong intrinsic muscles and pulls the foot out of foot pronation the performance of that athlete will be enhanced on the ice. This was demonstrated by the findings of this study, as both the foot core exercise and traditional exercise groups showed significant decreases from pre-to-post testing for the agility test. This could be attributed to the navicular drop findings as most of the subjects presented at the end of the study with a neutral foot posture instead of in pronation. Therefore, the exercises might have provided a more functional foot for both groups by decreasing foot pronation while skating. However, during the pre and post testing of this agility test, it was not observed whether the athletes were skating on the medial or lateral edge of the skate throughout the test. The S-cornering agility test showed significant changes for test with the group effect size being small and both groups demonstrated moderate effect sizes for time. There were no significant changes present within this study between groups and the results did not favor one group over the other. Over the course of this 4week intervention period, there seems to be a positive change that could be continued in order to meet clinically meaningful change.

Clinical Implications 
Both the foot core group and traditional group showed no change pretest to posttest in the patient-oriented outcomes of the FAAM ADL and Sport. However, both groups improved pretest to posttest in all clinically oriented outcomes of navicular drop, balance and agility, which may have more relevance in the clinical setting than statistical significance when considering which exercises to utilize during rehabilitation or preventative programs. Based on the effect sizes demonstrated, the foot core group was favored over the traditional group for navicular drop, the PL direction of the SEBT and agility. The traditional group was favored over the foot core group within the A and PM directions of the SEBT, based on the effect sizes. In a four-week program, beneficial improvements were demonstrated for navicular drop, balance and agility. Therefore, the utilization of the foot core exercises, traditional exercises, or a combination of all exercises that were used in this study should be incorporated into an ice hockey pre-season program in order to enhance the athlete's performance, balance and foot posture. Although the short foot and toe-spread-out exercises are beneficial at targeting the intrinsic muscles and the towel curl and foam pick up exercises target extrinsic and some intrinsic muscles, all exercises utilized within this study are beneficial for the biomechanical aspects of the foot. Combination of exercise techniques is the typical method of rehabilitation programs and should be the cornerstone of a preventative program utilized for ice hockey teams. It is recommended that athletic trainers of ice hockey teams utilize a combination of the foot core exercises and traditional exercises in a program at the beginning of the season in order to enhance the athlete's performance through balance, foot posture and agility throughout the entirety of the season.

\section{Limitations}

Limitations have been identified in this study. The primary limitation of the present study is that there was only 1 university team with the same skill level utilized with a small sample 
size. This study utilized a sample of convenience at one university of only healthy D1 and D2 ice hockey athletes. While the sample was of convenience, scheduling sessions during data collection was a challenge due to class and work schedules as well as some subjects lacking efficient transportation to the site of data collection. There were multiple sessions where individuals from both groups were present during data collection due to lack of transportation for some. During this time the clinician separated the groups on opposite sides of the room to attempt to keep the groups separated during their interventions. Although blinding for subjects, therapists and assessors did not occur, all subjects exerted their best effort throughout the entirety of the study. When subjects from both groups were present while performing exercises, some did question why they were doing exercises involving towels and foam pieces while the others were just contracting their feet. However, with both groups being in the exercise session at the same time they were able to create a competitive environment trying to complete exercises more efficiently than the other. Short foot exercise and traditional exercise programs may vary based on a number of factors adding to individual variability including previous injury, rehabilitation history as well as current fitness level. Since this was the first study examining the impact on traditional and short foot exercises on ice hockey athlete performance, more studies should evaluate the impact these exercise programs have on ice hockey athlete's performance as well as when combined with other techniques.

\section{CONCLUSION}

The foot core exercise group and the traditional exercise group within this study improved pre to post testing for navicular drop, Star Excursion Balance Test and S-cornering agility test. The patient-oriented outcomes of the FAAM ADL and Sport showed no change for either group. Small, moderate and large effect sizes for both groups were evident throughout this 
study. One group was not favored over the other group in regard to effect sizes. The traditional exercise group demonstrated greater changes for the anterior direction of the SEBT. Both groups showed significant changes for navicular drop, posteromedial direction and posterolateral direction of the SEBT as well as the S-Cornering agility test. However, for the posteromedial and posterolateral directions of the SEBT and navicular drop test the left foot demonstrated greater changes for both the foot core and traditional exercise groups. With this, it can be determined that both the foot core exercises and traditional exercises provide a positive impact on balance, foot posture and agility within ice hockey athletes. Why changes occurred may be unknown as this is the first study using an ice hockey population rather than track and field athletes or those with chronic ankle instability. Future studies should be performed with larger sample sizes, a variety of skill levels and longer trial periods to gather additional information on the impacts these exercises have on ice hockey athletes. 


\section{REFERENCES}

1. Fraser JJ and Hertel J. Effects of a 4-week intrinsic foot muscle exercises program on motor function: A preliminary randomized control trial. J Sport Rehabil. 2019;28:339-349.

2. McKeon OP and Fourchet F. Freeing the foot integrating the foot core system into rehabilitation for lower extremity injuries. Clin Sports Med. 2015;34:347-36.

3. Fraser JJ, Feger MA, Hertel J. Midfoot and forefoot involvement in lateral ankle sprains and chronic ankle instability. Part 1: anatomy and biomechanics. Int J Sports Phys Ther. 2016;11(6):992-1005.

4. McKeon OP, Hertel J, Bramble D, Davis I. The foot core system: a new paradigm for understanding intrinsic foot muscle function. Br J Sports Med. 2015;49:290:1-9.

5. Fourchet $\mathrm{F}$ and Gojanovic B. Foot core strengthening: relevance in injury prevention and rehabilitation for runners. Swiss Sport Exerc Med. 2016;64(1):26-30.

6. Detton, Alan J. Grants Dissector. Wolters Kluwer Medical, 2017.

7. Mulligan PE and Cook GP. Effect of plantar intrinsic muscle training on medial longitudinal arch morphology and dynamic function. Man Ther. 2013;18:425-430.

8. Okamura K, Kanai S, Fukuda K, Tanaka S, Ono T, Oki S. The effect of additional activation of the plantar intrinsic foot muscles on foot kinematics in flat-footed subjects. Foot. 2019;38:19-20.

9. Soysa A, Hiller Claire, Refshauge K, Burns J. Importance and challenges of measuring intrinsic foot muscle strength. J Foot Ankle Res. 2012;5(29):1-14.

10. Gooding MT, Feger AM, Hart MJ, Hertel J. Intrinsic foot muscle activation during specific exercises: A T2 magnetic resonance imaging study. J Athl Train. 2016;51(8):644-650.

11. Unver B, Erdem EU, Akbas E. Effects of short-foot exercises on foot posture, pain, disability, and plantar pressure in pes planus. J Sport Rehabil. 2019.

12. Humble N. Podiatric management in ice skating. Sport Pod. 2003:49-63.

13. Buckeridge E, LeVangie CM, Stetter B, Nigg RS, Nigg MB. An on-ice measurement approach to analyse the biomechanics of ice hockey skating. PLOS ONE. 2015;10(5):1-16.

14. Carcia CR, Martin RL, Drouin JM. Validity of the foot and ankle ability measure in athletes with chronic ankle instability. J Athl Train. 2008;43(2):179-183. 
15. Martin RL, Irrgang JJ, Burdett RG, Conti SF, Van Swearingen JM. Evidence of validity for the foot and ankle ability measure (FAAM). Foot Ankle Int. 2005;26(11):968-983.

16. Lynn KS, Padilla AR, Tsang KWK. Differences in static- and dynamic-balance task performance after 4 weeks of intrinsic foot muscle training: The short foot exercise versus the towel curl exercise. J Sport Rehabil. 2012;21:327-333.

17. Matias AB, Taddei AT, Duarte M, Sacco ICN. Protocol for evaluating the effects of a therapeutic foot exercises program on injury incidence, foot functionality and biomechanics in long-distance runners: a randomized control trial. BMC Musculo Dis. 2016;17(160):1-11.

18. Zuil-Escobar JC, Martinez-Cepa CB, Martin-Urrialde JA, Gomez-Conesa A. Medial longitudinal arch: Accuracy, reliability, and correlation between navicular drop test and footprint parameters. J Manipulative Physiol Ther. 2018;41(8):672-679.

19. Eichelberger P, Blasimann A, Lutz N, Krause F, Baur H. A minimal marker set for threedimensional foot function assessment: measuring navicular drop and drift under dynamic conditions. J Foot Ankle Res. 2018;11(15):1-10.

20. Earl JE and Hertel J. Lower-extremity muscle activation during the star excursion balance tests. J Sport Rehabil. 2001;10:93-104.

21. Eriksrud O, Federolf P, Anderson P, Cabri J. Hand reach star excursion balance test: an alternative test for dynamic postural control and functional mobility. PLOS ONE. 2018;13(5):1-18.

22. McKeon PO, Ingersoll CD, Kerrigan DC, Saliba E, Bennet BC, Hertel J. Balance training improves function and postural control in those with chronic ankle instability. Med Sci Sports Exerc. 2008;1810-1819.

23. Kinzey SJ and Armstrong CW. The reliability of the star-excursion test in assessing dynamic balance. J Orthop Sport Phys. 1998;27(5):356-360.

24. Powden CJ, Dodds TK, Gabriel EH. The reliability of the star excursion balance test and lower quarter Y-balance test in healthy adults: a systematic review. Int J Sport Phys Ther. 2019;14(5):683-694.

25. Hegedus EJ, McDonough SM, Bleakley C, Baxter D, Cook CE. Clinician-friendly lower extremity physical performance tests in athletes: a systematic review of measurement properties and correlation with injury. Part 2 - the tests for the hip, thigh, foot, and ankle including the star excursion balance test. Br J Sports Med. 2015;49(10).

26. Kivlan BR and Martin RL. Functional performance testing of the hip in athletes: a systematic review for reliability and validity. Int J Sport Phys Ther.2012;7(4):402-412. 
27. Gribble PA, Hertel J, Plisky P. Using the star excursion balance test to assess dynamic postural control deficits and outcomes in lower extremity injury: a literature and systematic review. J Athl Train. 2012;47(3):339-357.

28. Janot JM, Beltz NM, Dalleck LD. Multiple off-ice performance variables predict on-ice skating performance in male and female division III ice hockey players. J Sport Sci Med. 2015;14:522-529.

29. Okamura K, Kanai S, Hasegawa M, Otsuko A, Oki S. The effect of additional activation of the plantar intrinsic foot muscles on foot dynamics during gait. Foot. 2018;34:1-5. 
APPENDICES 


\section{APPENDIX A}

\section{THE PROBLEM}

Research Question

The foot is very intricate and complex due to the bony, ligamentous, tendon, neural and muscular components that surround and shape the foot. To differentiate between these structures, it is imperative to understand first the anatomy and function of the extrinsic and intrinsic muscle groups. The extrinsic group consists of the muscles that originate in the lower leg portion of the body and cross the ankle joint to insert on the foot. 4 The extrinsic muscles primarily function as global movers. With being a global mover, the extrinsic muscles generate larger movements compared to intrinsic muscles. The extrinsic muscles also consist of large cross-sectional areas and large moment arms, which allow absorption and propulsion during the gait phases, and provide slight support to the medial longitudinal arch (MLA).4,5,8 With small moment arms and cross-sectional areas, the intrinsic muscles differ from the extrinsic muscles, creating different roles to perform for the human body.5 The intrinsic muscles act as the primary stabilizers. These muscles are organized into four layers on the plantar aspect of the foot.9The first layer is the most superficial and consists of the abductor hallucis, flexor digitorum brevis and the abductor digiti minimi. The second layer includes the quadratus plantae and the lumbricals. The third layer consists of the adductor hallucis oblique, flexor hallucis brevis and flexor digiti minimi brevis. The deepest layer, the fourth layer, is made up of the three plantar interossei muscles.9 These muscles include abductor hallucis, flexor digitorum brevis, adductor digiti minimi, quadratus plantae, lumbricals, flexor digiti minimi, adductor hallucis brevis, flexor hallucis brevis, plantar interossei, dorsal interossei, and extensor digitorum brevis. 4 These muscles all originate and insert on the plantar or dorsal surface of the foot, not crossing the ankle joint. 4 
There are three subsystems that shape the foot: the active, the passive and the neural subsystems.4,5 Within the active subsystem there contains the muscles and tendons that attach on the foot, or the extrinsic and intrinsic muscles. The passive subsystem goes into the other anatomical structures present such as the bones of the arches, the plantar fascia, and the ligaments.4,5 Within the passive subsystem, four distinct arches are created through the configuration of the tarsal and metatarsal bones. These arches are the medial longitudinal arch, lateral longitudinal arch, anterior transverse metatarsal arch, and posterior transverse metatarsal arch. 4 The lateral longitudinal arch and medial longitudinal arch are in the sagittal plane from the rearfoot to the forefoot. The transverse arches are located on the coronal plane in the forefoot and are comprised of five metatarsal heads.30 The neural subsystems include the sensory receptors that are within the active and passive subsystems. The sensory receptors of the neural subsystems are also described as the musculotendinous receptors, ligamentous receptors and plantar cutaneous receptors and are important for plantar tactile sensitivity. 4,5

The primary structure that determines the stability of the foot is the MLA. This structure is often known for stability, energy storage and release during gait phases, and raising the center of mass through recoiling and release. The MLA is comprised of the calcaneus, talus, navicular, medial cuneiform, first metatarsal, plantar aponeurosis, long and short plantar ligaments, and the spring ligament.7 The configuration of these bones and ligaments create the framework of the MLA. Both the intrinsic and extrinsic muscle groups of the foot then control the MLA.5 The MLA is specifically supported through the anterior and posterior tibialis, fibularis longus and the plantar intrinsic foot muscle groups.7 Therefore, if any of these muscles fail to contract or are weak, a collapse in the MLA will occur putting the foot in an excessive pronated position. 7 It is crucial to have a stable base for all activities, and the intrinsic muscles are the main source of 
that base stability. These intrinsic plantar muscles control arch deformation velocity and degree, allowing more stability by activating the MLA.4,11 Intrinsic muscles play a large role in sensory information due to the stretch response for foot posture. The locations and actions of these muscles help with gait patterns, support of the arches, activities, and load placed on structures.4 To measure the height of the MLA, a navicular drop test is typically utilized, which can demonstrate fatigue or weakness in any of the muscles that support the MLA.31

The biomechanical and functional properties of the intrinsic foot muscles are separate from the extrinsic foot muscles.32 Therefore, in order to activate the intrinsic foot muscles properly, an understanding of the anatomy, evaluation, and activation of these muscles must be present. McKeon et al.4 reported that short foot exercises may be one form of exercise that strengthens those intrinsic muscles. Short foot exercise efficiently activated the abductor hallucis and prevented the excessive pronation motion of the foot by lifting the MLA.7,11 McKeon et al.4 emphasized the importance of the patient understanding when in subtalar neutral and correctly activating intrinsic muscles by lifting the arch. If understanding is present, then it is easier to replicate and perform at home. 4 In addition to replication, there should also be a progression from seated, standing, standing on one leg, and then with functional activities such as squatting and jumping.4

All three subsystems will become involved during the mechanism of an ankle or foot injury. Although damage may depend on severity of the injury itself, it is important to understand each layer that comprises the foot, especially when deciding on rehabilitation techniques. With the activation of these plantar intrinsic foot muscles, improvements in dynamic alignment, control of arch positioning and balance abilities will be present.7 The short foot exercise targets the intrinsic muscles of the foot and enables more stabilization through the 
MLA, a reduction in excessive foot pronation and foot disability, and an increase in plantar force dispersion at the midfoot by neuromuscular control during weight bearing activities.7,11Thus, the benefits of the short foot exercise make it a key aspect of rehabilitation for ankle and foot injuries. Some of these benefits are improved balance and foot function and a reduction in arch collapse by allowing for an increase in support of the foot and ankle, and a decrease risk of falling into excessive foot pronation. 4

Ice hockey is a sport that requires specific biomechanical techniques to perform the sport correctly. It is a sport that is fast and dynamic, requiring an immense amount of stability. 33 As with any sport that uses skating as a form of propulsion, the maintenance of balance and stability on a very narrow base of support, such as the blade on a skate, is imperative. This narrow base of support limits the athlete's biomechanical stability.12,33 In order to balance over such a small blade, the utilization of eccentric muscle control and proprioceptive skills is necessary.12 Ice hockey athletes are required to skate on that small balance point, forwards, backwards and sideways. At times, the eccentric muscle control and proprioceptive skills may become strenuous for the ice hockey player because of the constant need for stability on such a limited base of support. Therefore, intrinsic foot muscles may become fatigued due to overwork and stress. Thus, strains of the intrinsic muscles of the foot are commonly seen in ice hockey athletes due to a fatiguing effect.12 Although it is difficult to relate gait patterns to ice hockey, as athletes are in skates and glide rather than walk or run, ice hockey players still utilize plantar force application. An important aspect of skating in ice hockey is to push off with the toes for proper propulsion in the stride. Therefore, dispersion of forces throughout the foot are a crucial aspect of hockey that may be overlooked.13 
Balance is an important aspect when it comes to ice hockey athletes. In fact, balance is one of the crucial factors in ice hockey.33 In order to acquire the correct skating techniques and stability on the ice, an intricate level of balance is required.33 When an ice hockey player is skating, the amount of time spent on the lateral edge of the skate impacts power and efficiency acquired while skating. Therefore, when an ice hockey athlete's arch drops creating a foot pronation position more time will be spent on the medial aspect of the skate and decreases in power and efficiency in performance will be demonstrated.12

Recently, the literature on the intrinsic foot muscles and how to incorporate beneficial strengthening exercises using foot core has become evident. By strengthening the intrinsic foot muscles, balance, foot posture and stability are impacted. Despite the importance of balance in ice hockey athletes and how it is related to performance levels on the ice, research is limited. Further, there is a lack of research on strengthening the intrinsic muscles of the foot and the benefits to ice hockey players. As an increase in foot pronation demonstrated a decrease in certain performance aspects in an ice hockey player, activation of the foot intrinsic muscles may demonstrate a decrease in excessive foot pronation and navicular drop with an increase in MLA stability, neuromuscular control and plantar force dispersion at the mid foot.7,11,12 With this impact, strengthening of the intrinsic muscles of the foot, or the utilization of foot core, should be explored to assess the effects on performance in ice hockey athletes. Currently, there is no research on foot core strengthening exercise and the effect on ice hockey performance. Thus, the following research questions were asked:

Research Questions

1. Does activation of the foot intrinsic muscles through foot core decrease foot pronation in ice hockey athletes through measurements of navicular drop? 
2. Does utilizing the foot core exercises to strengthen the foot intrinsic muscles enable ice hockey players to experience an increase in agility on the ice?

3. Does strengthening the intrinsic muscles of the foot through the foot core exercises help ice hockey players improve balance and stability on the Star Excursion Balance Test?

4. Does the utilization of the foot core exercise show greater increases in balance and perceived ability when compared to more traditional methods of rehabilitation (i.e. towel scrunches, marble pick-ups, etc.)?

Experimental Hypotheses

1. The foot core exercise group will show a decrease in navicular drop pre-to-posttest after a 4-week intervention (i.e. a decrease in foot pronation).

2. A decrease in time on the S-cornering agility drill will be observed for those in the foot core exercise group pre-to-posttest after a 4-week intervention.

3. An increase in distance in posteromedial and posterolateral on the SEBT will be observed from the foot core exercise group after a 4-week intervention.

4. The foot core exercise group will demonstrate increases in perceived ability on the sport specific section of the FAAM questionnaire pre-to-posttest when compared to the traditional rehabilitation group after a 4-week intervention.

5. The foot core exercise group will demonstrate minimal increases in perceived ability on the activities of daily living section of the FAAM questionnaire pre-to-posttest when compared to the traditional rehabilitation group after a 4-week intervention.

\section{Assumptions}

1. All subjects will meet the inclusion criteria for the research study.

2. All subjects will participate throughout the entire research study.

3. All subjects will perform to the best of their ability during the research study.

4. The instruments and techniques being utilized will be valid and reliable.

5. Assessment tests will be performed identically on all subjects.

6. The documentation throughout the research study will be accurate.

Delimitations 
1. The subject population will be limited to only male ice hockey athletes from DI and DII club teams at one college in a Mid-Atlantic state.

2. The subjects will only be between the age ranges of 18 to 24 .

\section{Operational Definitions}

1. Agility - The ability to efficiently perform through obstacles and exercises with proper stability.33

2. Anterior tibialis tendon - One of the active structures that inserts onto the medial cuneiform and first metatarsal bones acting as a support system for the arches.2,4,11

3. Balance - Obtaining postural stability and control throughout the body.21

4. Club team - A team that is not administered through the athletics department of a university and consists of students that are officially enrolled at the university affiliated with the club team.

5. Extrinsic muscles - Muscles whose tendons cross the ankle joint creating large moment arms and cross-sectional areas, with the importance of being movers.4,5

6. Fibularis longus tendon - One of the active structures that inserts onto the medial cuneiform and first metatarsal bones creating support to the arches.2,4,11

7. Foot core - Active, passive and neural structures of the foot that provide dynamic foot control.4,7,11

8. Intrinsic muscles - Muscles that originate and insert on the foot without crossing the ankle joint that consist of small moment arms and cross-sectional areas, with the importance of being stabilizers. 4,5

9. Medial longitudinal arch (MLA) - One of the three arches of the foot that is the main provider for stability, energy storage, and force distribution throughout the foot. The MLA is supported through the calcaneus, talus, navicular, medial cuneiform, first metatarsal, plantar aponeurosis, long and short plantar ligaments, and the spring ligament.4,7,31

10. Ligaments - Passive tissues that connect bones allowing for the configuration of the arches of the foot.4,5,32

11. Posterior tibialis tendon - One of the active structures that inserts onto the navicular tuberosity and the medial cuneiform as a support for the MLA.4,5,7 
12. Pronation - Arch collapse that occurs due to weakening of the intrinsic muscles of the foot putting the weight of the foot excessively on the medial aspect, specifically the navicular bone of the MLA.2,7,12

13. Short foot - Strengthening exercises that target the intrinsic muscles of the foot to provide stability, balance, proprioception and dynamic control.2,4,11

14. Subsystems - The division of the structures of the foot into active, passive and neural sections. 4,5

15. Supination - A motion putting the weight of the foot excessively on the lateral aspect through inversion, adduction and plantarflexion. 2,7,12

16. Traditional foot rehabilitation - Methods of rehabilitation that focus on all muscles of the foot and ankle, or extrinsic and intrinsic muscles. (i.e. towel scrunches and marble pickups).4

Limitations

1. Participants can drop out at any time.

2. Subjects may not give $100 \%$ during exercises.

3. Limited research on effects of intrinsic muscle strengthening on ice hockey athletes.

4. The study may not be generalizable to other athletes in different populations.

5. No evidence-based specific short foot exercises exist as to what should be included.

6. The assessor/therapist was not blinded to group assignment.

7. This was only a four-week training program.

Significance of the Study

Ice hockey is a sport that revolves around proper balance, stability and quick agile movements. Activation of the foot intrinsic muscles has demonstrated increases in balance, MLA stability, neuromuscular control and plantar force dispersion at the midfoot. Research should be conducted on how the incorporation of foot core exercises affect an ice hockey players agility and performance on the ice. Benefits from this study may reveal utilizing the foot core exercises 
with an ice hockey team can aid in improving performance for the team in terms of balance and agility on the ice. This study may also reveal beneficial methods of preventing possible foot injuries by decreasing the risk of players falling into excessive foot pronation. Future researchers should be able to apply the results of this study to conduct additional studies on ice hockey athletes to determine the effectiveness of short foot exercises on ice hockey performance.

At completion of this study, dissemination of the information that is provided will occur. The information from this study will have a direct effect on ice hockey athletes and coaches to better understand proper methods of increasing athletes' performance on the ice. This information will also be beneficial for athletic trainers, or clinicians, working with ice hockey teams of all performance levels in order to increase levels of balance, agility and performance in ice hockey athletes. Both athletes and athletic trainers will benefit from this study as the potential for decrease risk of foot and ankle injuries through decreasing excessive foot pronation may occur. To further benefit clinicians, athletes and coaches of ice hockey teams, this information can be presented in journals, workshops or conferences. 


\section{APPENDIX B}

\section{LITERATURE REVIEW}

Introduction

The ability of the foot to absorb and propel the body through ground force reactions is due to the complex make-up of the foot.2 The foot is comprised of a multitude of structures that provide function and allow the performance of tasks that are placed on it. Dynamic foot control and function are due to the interaction between active, passive and neural structures located within the foot.2 While controlling the configuration of the foot, motor and sensory information become a vital part of the process. Sensorimotor control becomes apparent within the foot due to the multiple interacting systems. In order to allow greater adaptability at the foot, multiple degrees of freedom must be present with functional variability in that no one degree of freedom is stressed more than any other.2 If this balance is not created, and a loss of degrees of freedom is present, damage to the tissues within the foot will then occur. This further creates injury, affecting performance, stability and function.

The structures that provide stabilization and function throughout the foot are the intrinsic muscles.1 These intrinsic muscles originate and insert within the foot on the dorsal and plantar surfaces, and do not cross the ankle joint.2 The intrinsic muscles have impacted lower extremity pathologies and injuries as well as balance.34 Improvements in balance are demonstrated with strengthening intrinsic muscles by optimizing the foot's contact with the floor as well as improving dynamic alignment, controlling arch position and stimulation of proprioceptors within the sole of the foot.7 This literature review will discuss the importance of the foot core and intrinsic muscles, specifically in regard to ice hockey athletes. Specific anatomy, biomechanical 
properties, traditional rehabilitation methods, foot core exercises, and functional rehabilitation will be discussed in detail.

Anatomy

The complex nature of the foot begins with the bony configuration. This starts proximally with the tibia and fibula of the lower leg. Moving distally the seven tarsal bones, which are the calcaneus, talus, navicular, medial cuneiform, intermediate cuneiform, lateral cuneiform, and cuboid bones. Distal from the tarsal bones are the five metatarsal bones. 6 These begin with the first metatarsal on the medial aspect of the foot and ends at the fifth metatarsal on the lateral aspect. Located distally to the metatarsal bones are the fourteen phalanges. The second through the fifth toes have three phalanges, while the first toe only has two. These can further be categorized into the distal, middle and proximal phalanges.6 These bones form together to create joints at the foot and ankle.3 The tibia and fibula form a "mortise" proximal to the ankle, which then connects with the talus. This configuration forms the talocrural joint, which allows for plantar flexion and dorsiflexion osteokinematic motions to occur at the ankle.3 The talocrural joint has an oblique axis of rotation that is located through the medial malleolus, the head of the talus, and the lateral malleolus.3 Due to this oblique axis of rotation, dorsiflexion often occurs with eversion and adduction of the foot, while plantarflexion occurs with inversion and abduction of the foot. 3

The hindfoot, or rearfoot, is a configuration of the talus, the subtalar joint as well as the calcaneus.3,6 The subtalar joint is comprised of talocalcaneonavicular articulation anteriorly and talocalcaneal articulation posteriorly allowing for pronation and supination motions to occur at this joint. These two articulations are separated through the tarsal canal.3 The axis of rotation for the subtalar joint transects through the three cardinal planes, or the frontal, transverse and sagittal 
planes.2,3 With this axis of rotation, pronation occurs with dorsiflexion while supination occurs with plantar flexion and adduction. 3 The forefoot is the anterior aspect of the foot. This consists of the five metatarsal bones and fourteen phalanges as well as the two sesamoid bones that act as a pulley for the tendons leading to the $1_{\text {st }}$ toe.3,6 The forefoot aids in the gait cycle by being the main point of push-off and providing efficient leverage for the human body during gait patterns.2,3,6 The articulation between the forefoot and rearfoot is due to the transverse tarsal joint, which is comprised of the talus, navicular, calcaneus and cuboid.3,6 Two separate axes of rotation occur at this joint. One is through the longitudinal axis with supination and pronation while the other is around the oblique axis with cuboid translation on the calcaneus.2,3 The midfoot is then comprised of the navicular, medial, intermediate and lateral cuneiforms as well as the cuboid. The boney configuration of the midfoot creates the arches of the foot, which then form a half dome.3,6

Ligamentous structures are located all around the foot. The ligaments that are of importance to the foot core are the ligaments that provide support to the arches of the foot. The arches in the foot provide support through the long and short plantar ligaments as well as the calcaneonavicular ligament.2 The long and short plantar ligaments are located on the plantar surface of the foot below the flexor digitorum brevis and quadratus plantae muscles.6 The long and short plantar ligaments connect the calcaneus to the cuboid. The plantar calcaneonavicular ligament, also known as the spring ligament, is located on the plantar aspect of the foot connecting the calcaneus to the navicular.6 The calcaneonavicular ligament, the fibularis longus tendon and the tibialis posterior tendon work together to support the head of the talus and the longitudinal arch.6 
The ligamentous structures provide support to all joints of the foot and ankle. In regard to the talocrural joint, the deltoid ligament, anterior talofibular ligament, calcaneofibular ligament and posterior talofibular ligament provide static support to the joint.2,3 The subtalar joint is statically supported through the interosseous talocalcaneal, posterior talocalcaneal, lateral talocalcaneal, calcaneofibular, and fibular talocalcaneal ligaments. 3,4 The transverse tarsal joint is also statically supported through ligamentous structures. These ligaments include the bifurcate, dorsal calcaneocuboid, dorsal talonavicular, interosseous talocalcaneal, deltoid, spring and plantar cuboideonavicular ligaments. 3,4

Throughout the configuration of the tarsal and metatarsal bones of the foot, four distinct arches are created.3,4 These arches are the medial longitudinal arch (MLA), lateral longitudinal arch, anterior transverse metatarsal arch, and posterior transverse metatarsal arch.4 These arches form a half dome on the plantar aspect of the foot and are supported through the bones and muscles of the foot.3,7 The lateral longitudinal arch and medial longitudinal arch are constructed on the sagittal plane from the rearfoot to the forefoot. The transverse arches are located on the coronal plane in the forefoot and include the five metatarsal heads. 30 The arches of the foot allow for transmission of forces as well as allow the foot to accommodate to a variety of different grounds and forces.3

The primary structure that provides the stability of the foot is the MLA. The MLA is comprised of the calcaneus, talus, navicular, medial cuneiform, first metatarsal, plantar aponeurosis, long and short plantar ligaments, and the spring ligament. 7 The configuration of these bones and ligaments create the framework of the MLA. The MLA is often known for the role in stability, energy storage and release during gait phases, and raising the center of mass through recoiling and release. 5 The MLA assists in the push off of the gait cycle in high velocity 
activities through shortening the foot and increasing the angle of the arch. Through this, the lever arm of the MLA is optimized, creating ideal push off.3 During lower velocity activities of the foot, the MLA is lengthened. The flattening that occurs at the MLA during these low velocity activities allows for accommodation of the foot to uneven terrain as well as an increase in balance. 3,4

Both the intrinsic and extrinsic muscle groups of the foot control the MLA.5 The MLA is specifically supported through the anterior and posterior tibialis, fibularis longus and the plantar intrinsic foot muscle groups.5,7,29 Therefore, if any of these muscles fail to contract or are weak, a collapse in the MLA will occur putting the foot in an excessive pronated position.5,7,11 It is crucial to have a stable base for all activities, and the intrinsic muscles are the main source of that base stability. These intrinsic plantar muscles control arch deformation velocity and degree, allowing more stability by activating the MLA.4,11,29 Intrinsic muscles play a large role in sensory information due to the stretch response for foot posture. The locations and actions of these muscles help with gait patterns, support of the arches, activities, and load placed on structures.4,11

As depicted in Table B1, the extrinsic muscle group consists of the muscles that originate in the lower leg portion of the body and cross the ankle joint to insert on the foot.4 The extrinsic muscles primarily function as global movers. With being a global mover, the eleven extrinsic muscles generate larger movements compared to intrinsic muscles. The extrinsic muscle group of the foot act to evert, invert, abduct, adduct, plantar flex, dorsiflex and supinate the foot and ankle as well as flex and extend all the digits of the foot.6,35 The extrinsic muscles also consist of large cross-sectional areas and large moment arms, which allow absorption and propulsion 
during the gait phases, and provide slight support to the MLA.4,5,8 These muscles act on the foot to provide some support to the transverse arch of the foot as well as the MLA.6,35

Table B1. Extrinsic Muscles of the Foot 6,35

\begin{tabular}{|c|c|c|c|c|c|}
\hline Muscle & Origin & Insertion & Action & $\begin{array}{c}\text { Blood } \\
\text { Supply }\end{array}$ & Innervation \\
\hline $\begin{array}{l}\text { Fibularis } \\
\text { Longus }\end{array}$ & $\begin{array}{l}\text { Head of } \\
\text { fibula and } \\
\text { upper half } \\
\text { of the } \\
\text { fibular shaft }\end{array}$ & $\begin{array}{l}\text { Posterolateral } \\
\text { aspect of medial } \\
\text { cuneiform and } \\
\text { lateral portion of } \\
\text { base of first } \\
\text { metatarsal }\end{array}$ & $\begin{array}{l}\text { Eversion and } \\
\text { plantar } \\
\text { flexion of the } \\
\text { foot, and } \\
\text { provides } \\
\text { support to } \\
\text { the } \\
\text { transverse } \\
\text { arch }\end{array}$ & $\begin{array}{l}\text { Anterior } \\
\text { tibial artery }\end{array}$ & $\begin{array}{l}\text { Superficial } \\
\text { fibular nerve }\end{array}$ \\
\hline $\begin{array}{l}\text { Fibularis } \\
\text { Brevis }\end{array}$ & $\begin{array}{l}\text { Inferior } \\
\text { two-thirds } \\
\text { of the } \\
\text { lateral } \\
\text { fibula and } \\
\text { posterior } \\
\text { lateral } \\
\text { malleolus of } \\
\text { the fibula }\end{array}$ & $\begin{array}{l}\text { The styloid } \\
\text { process of the } \\
\text { fifth metatarsal }\end{array}$ & $\begin{array}{l}\text { Eversion and } \\
\text { plantar } \\
\text { flexion of the } \\
\text { foot }\end{array}$ & $\begin{array}{l}\text { Fibular } \\
\text { artery }\end{array}$ & $\begin{array}{l}\text { Superficial } \\
\text { fibular nerve }\end{array}$ \\
\hline $\begin{array}{l}\text { Fibularis } \\
\text { Tertius }\end{array}$ & $\begin{array}{l}\text { Middle } \\
\text { fibular shaft }\end{array}$ & $\begin{array}{l}\text { Dorsal surface of } \\
\text { fifth metatarsal }\end{array}$ & $\begin{array}{l}\text { Dorsiflexion, } \\
\text { eversion and } \\
\text { abduction of } \\
\text { the foot }\end{array}$ & $\begin{array}{l}\text { Anterior } \\
\text { tibial artery }\end{array}$ & $\begin{array}{l}\text { Deep fibular } \\
\text { nerve }\end{array}$ \\
\hline $\begin{array}{l}\text { Anterior } \\
\text { Tibialis }\end{array}$ & $\begin{array}{l}\text { Lateral } \\
\text { condyle of } \\
\text { tibia and } \\
\text { proximal } \\
\text { half/two- } \\
\text { thirds of } \\
\text { tibial shaft }\end{array}$ & $\begin{array}{l}\text { Medial and } \\
\text { plantar surfaces } \\
\text { of the medial } \\
\text { cuneiform and } \\
\text { base of the first } \\
\text { metatarsal }\end{array}$ & $\begin{array}{l}\text { Dorsiflexion } \\
\text { of the ankle } \\
\text { and inversion } \\
\text { of the } \\
\text { hindfoot }\end{array}$ & $\begin{array}{l}\text { Anterior } \\
\text { tibial artery }\end{array}$ & $\begin{array}{l}\text { Deep fibular } \\
\text { nerve }\end{array}$ \\
\hline $\begin{array}{l}\text { Posterior } \\
\text { Tibialis }\end{array}$ & $\begin{array}{l}\text { Superior } \\
\text { two-thirds } \\
\text { of the } \\
\text { medial } \\
\text { posterior } \\
\text { surface of } \\
\text { the tibia }\end{array}$ & $\begin{array}{l}\text { Navicular } \\
\text { tuberosity } \\
\text { (superficial slip) } \\
\text { and metatarsals } \\
\text { 2-4 plantar } \\
\text { surfaces (deep } \\
\text { slip) }\end{array}$ & $\begin{array}{l}\text { Inversion, } \\
\text { adduction, } \\
\text { plantar } \\
\text { flexion and } \\
\text { supination of } \\
\text { the foot }\end{array}$ & $\begin{array}{l}\text { Sural, } \\
\text { fibular and } \\
\text { posterior } \\
\text { tibial } \\
\text { arteries }\end{array}$ & Tibial nerve \\
\hline
\end{tabular}




\begin{tabular}{|c|c|c|c|c|c|}
\hline $\begin{array}{l}\text { Extensor } \\
\text { Digitorum } \\
\text { Longus }\end{array}$ & $\begin{array}{l}\text { Lateral } \\
\text { tibial } \\
\text { condyle }\end{array}$ & $\begin{array}{l}\text { Dorsum of the } \\
\text { middle and } \\
\text { distal phalanges }\end{array}$ & $\begin{array}{l}\text { Extension of } \\
\text { the second- } \\
\text { fifth digits } \\
\text { and } \\
\text { dorsiflexion } \\
\text { of the ankle }\end{array}$ & $\begin{array}{l}\text { Anterior } \\
\text { tibial artery }\end{array}$ & $\begin{array}{l}\text { Deep fibular } \\
\text { nerve }\end{array}$ \\
\hline $\begin{array}{l}\text { Flexor } \\
\text { Digitorum } \\
\text { Longus }\end{array}$ & $\begin{array}{l}\text { Posterior } \\
\text { surface of } \\
\text { the tibia } \\
\text { distal to the } \\
\text { popliteal } \\
\text { line }\end{array}$ & $\begin{array}{l}\text { Plantar surfaces } \\
\text { of the bases of } \\
\text { the second-fifth } \\
\text { distal phalanges }\end{array}$ & $\begin{array}{l}\text { Flexion of } \\
\text { digits two- } \\
\text { five and } \\
\text { plantar } \\
\text { flexion of the } \\
\text { ankle }\end{array}$ & $\begin{array}{l}\text { Posterior } \\
\text { tibial artery }\end{array}$ & Tibial nerve \\
\hline $\begin{array}{l}\text { Flexor } \\
\text { Hallucis } \\
\text { Longus }\end{array}$ & $\begin{array}{l}\text { Inferior } \\
\text { two-thirds } \\
\text { of the } \\
\text { posterior } \\
\text { fibula }\end{array}$ & $\begin{array}{l}\text { Plantar surface } \\
\text { of the base of the } \\
\text { distal phalanx of } \\
\text { the great toe }\end{array}$ & $\begin{array}{l}\text { Flexion of } \\
\text { the great toe }\end{array}$ & $\begin{array}{l}\text { Fibular and } \\
\text { posterior } \\
\text { tibial artery }\end{array}$ & Tibial nerve \\
\hline Gastrocnemius & $\begin{array}{l}\text { Femoral } \\
\text { condyles }\end{array}$ & $\begin{array}{l}\text { Achilles } \\
\text { tendon/calcaneus }\end{array}$ & $\begin{array}{l}\text { Plantar } \\
\text { flexion of the } \\
\text { ankle }\end{array}$ & $\begin{array}{l}\text { Sural } \\
\text { branch of } \\
\text { the } \\
\text { popliteal } \\
\text { artery }\end{array}$ & Tibial nerve \\
\hline Soleus & $\begin{array}{l}\text { Upper } \\
\text { quarter of } \\
\text { the } \\
\text { posterior } \\
\text { fibula and } \\
\text { middle third } \\
\text { of the } \\
\text { posterior } \\
\text { tibial shaft }\end{array}$ & $\begin{array}{l}\text { Achilles } \\
\text { tendon/calcaneus }\end{array}$ & $\begin{array}{l}\text { Plantar } \\
\text { flexion of the } \\
\text { ankle }\end{array}$ & $\begin{array}{l}\text { Posterior } \\
\text { tibial, } \\
\text { fibular and } \\
\text { sural } \\
\text { arteries }\end{array}$ & Tibial nerve \\
\hline
\end{tabular}

Table B2 and B3 includes the origin, insertion, action and neurovascular innervation and circulation to the dorsal and plantar intrinsic muscles. These muscles all originate and insert within the structure of the foot.6,35 With small moment arms and cross-sectional areas, the intrinsic muscles differ from the extrinsic muscles by creating more of a stabilizing base instead of being a mover.5,6 The intrinsic muscles act as the primary stabilizers through support of the arches of the foot, creating stabilization throughout the entire foot. These muscles are organized 
into four layers on the plantar aspect of the foot.4,6,9 The first layer is the most superficial and consists of the abductor hallucis, flexor digitorum brevis and the abductor digiti minimi. The second layer includes the quadratus plantae and the lumbricals. The third layer consists of the adductor hallucis oblique, flexor hallucis brevis and flexor digiti minimi brevis. The deepest layer, the fourth layer, is made up of the three plantar interossei muscles.4,6,9 These muscles include abductor hallucis, flexor digitorum brevis, adductor digiti minimi, quadratus plantae, lumbricals, flexor digiti minimi, adductor hallucis brevis, flexor hallucis brevis, plantar interossei, dorsal interossei, and extensor digitorum brevis.4,6 These muscles all originate and insert on the plantar or dorsal surface of the foot, not crossing the ankle joint.4,6

Table B2. Dorsal Intrinsic Muscles of the Foot 6,35

\begin{tabular}{|c|c|c|c|c|c|}
\hline Muscle & Origin & Insertion & Action & Blood Supply & Innervation \\
\hline $\begin{array}{l}\text { Extensor } \\
\text { Digitorum } \\
\text { Brevis }\end{array}$ & $\begin{array}{l}\text { Dorsal } \\
\text { surface of the } \\
\text { calcaneus }\end{array}$ & $\begin{array}{l}\text { Base of the } \\
\text { proximal } \\
\text { phalanx of } \\
\text { digits two- } \\
\text { four }\end{array}$ & $\begin{array}{l}\text { Extension of } \\
\text { the toes }\end{array}$ & $\begin{array}{l}\text { Dorsalis } \\
\text { pedis }\end{array}$ & $\begin{array}{l}\text { Deep fibular } \\
\text { nerve }\end{array}$ \\
\hline $\begin{array}{l}\text { Dorsal } \\
\text { Interosseus }\end{array}$ & $\begin{array}{l}\text { Proximal half } \\
\text { of the sides } \\
\text { of adjacent } \\
\text { metatarsal } \\
\text { bones }\end{array}$ & $\begin{array}{l}\text { Bases of the } \\
\text { 2nd, 3rd, and } \\
\text { 4th proximal } \\
\text { phalanges } \\
\text { and the } \\
\text { aponeurosis } \\
\text { of the } \\
\text { tendons of } \\
\text { the extensor } \\
\text { digitorum } \\
\text { longus }\end{array}$ & $\begin{array}{l}\text { Abduction of } \\
\text { the } \\
\text { metatarsal- } \\
\text { phalangeal } \\
\text { joints }\end{array}$ & N/A & $\begin{array}{l}\text { Lateral } \\
\text { plantar nerve }\end{array}$ \\
\hline $\begin{array}{l}\text { Extensor } \\
\text { Hallucis } \\
\text { Brevis }\end{array}$ & $\begin{array}{l}\text { Dorsal } \\
\text { surface of the } \\
\text { calcaneus }\end{array}$ & $\begin{array}{l}\text { Base of the } \\
\text { proximal } \\
\text { phalanx of } \\
\text { the great toe }\end{array}$ & $\begin{array}{l}\text { Extension of } \\
\text { the great toe }\end{array}$ & $\begin{array}{l}\text { Dorsalis } \\
\text { pedis }\end{array}$ & $\begin{array}{l}\text { Deep fibular } \\
\text { nerve }\end{array}$ \\
\hline
\end{tabular}

Table B3. Plantar Intrinsic Muscles of the Foot 6,35

\begin{tabular}{|c|c|c|c|c|c|}
\hline Muscle & Origin & Insertion & Action & Blood & Innervation \\
\hline
\end{tabular}




\begin{tabular}{|c|c|c|c|c|c|}
\hline $\begin{array}{l}\text { 1st Layer } \\
\text { Abductor } \\
\text { Hallucis }\end{array}$ & $\begin{array}{l}\text { Calcaneal } \\
\text { tuberosity }\end{array}$ & $\begin{array}{l}\text { Base of the } \\
\text { great toe } \\
\text { and } \\
\text { proximal } \\
\text { phalanx }\end{array}$ & $\begin{array}{l}\text { Abduction of the } \\
\text { great toe }\end{array}$ & $\begin{array}{l}\text { Medial } \\
\text { plantar } \\
\text { artery }\end{array}$ & $\begin{array}{l}\text { Medial } \\
\text { plantar } \\
\text { nerve }\end{array}$ \\
\hline $\begin{array}{l}\text { Flexor } \\
\text { Digitorum } \\
\text { Brevis }\end{array}$ & $\begin{array}{l}\text { Calcaneal } \\
\text { tuberosity }\end{array}$ & $\begin{array}{l}\text { Middle } \\
\text { phalance of } \\
\text { digits two- } \\
\text { five }\end{array}$ & $\begin{array}{l}\text { Flexion of digits } \\
\text { two-five }\end{array}$ & $\begin{array}{l}\text { Medial } \\
\text { plantar } \\
\text { artery }\end{array}$ & $\begin{array}{l}\text { Medial } \\
\text { plantar } \\
\text { nerve }\end{array}$ \\
\hline $\begin{array}{l}\text { Abductor } \\
\text { Digiti } \\
\text { Minimi }\end{array}$ & $\begin{array}{l}\text { Calcaneal } \\
\text { tuberosity }\end{array}$ & $\begin{array}{l}\text { Base of the } \\
\text { fifth } \\
\text { metatarsal }\end{array}$ & $\begin{array}{l}\text { Abduction of the } \\
\text { fifth digit }\end{array}$ & $\begin{array}{l}\text { Lateral } \\
\text { plantar } \\
\text { artery }\end{array}$ & $\begin{array}{l}\text { Lateral } \\
\text { plantar } \\
\text { nerve }\end{array}$ \\
\hline $\begin{array}{l}\text { 2nd Layer } \\
\text { Quadratus } \\
\text { Plantae }\end{array}$ & $\begin{array}{l}\text { Plantar } \\
\text { surface of } \\
\text { the } \\
\text { calcaneus }\end{array}$ & $\begin{array}{l}\text { Flexor } \\
\text { digitorum } \\
\text { longus } \\
\text { tendon }\end{array}$ & $\begin{array}{l}\text { Flexion of distal } \\
\text { phalanges }\end{array}$ & $\begin{array}{l}\text { Lateral } \\
\text { plantar } \\
\text { artery }\end{array}$ & $\begin{array}{l}\text { Lateral } \\
\text { plantar } \\
\text { nerve }\end{array}$ \\
\hline Lumbricals & $\begin{array}{l}\text { Flexor } \\
\text { digitorum } \\
\text { longus } \\
\text { tendon }\end{array}$ & $\begin{array}{l}\text { Extensor } \\
\text { digitorum } \\
\text { longus } \\
\text { tendon }\end{array}$ & $\begin{array}{l}\text { Flexion of the } \\
\text { metatarsalphalangeal } \\
\text { joints and extension } \\
\text { of the } \\
\text { interphalangeal } \\
\text { joints }\end{array}$ & $\begin{array}{l}\text { Medial and } \\
\text { lateral } \\
\text { plantar } \\
\text { arteries }\end{array}$ & $\begin{array}{l}\text { Medial and } \\
\text { lateral } \\
\text { plantar } \\
\text { nerves }\end{array}$ \\
\hline $\begin{array}{l}\text { 3rd Layer } \\
\text { Flexor } \\
\text { Hallucis } \\
\text { Brevis }\end{array}$ & $\begin{array}{l}\text { Cuboid and } \\
\text { lateral } \\
\text { cuneiform }\end{array}$ & $\begin{array}{l}\text { Proximal } \\
\text { phalanx of } \\
\text { the great } \\
\text { toe }\end{array}$ & $\begin{array}{l}\text { Flexion of the great } \\
\text { toe }\end{array}$ & $\begin{array}{l}\text { Medial } \\
\text { plantar } \\
\text { artery }\end{array}$ & $\begin{array}{l}\text { Medial } \\
\text { plantar } \\
\text { nerve }\end{array}$ \\
\hline $\begin{array}{l}\text { Adductor } \\
\text { Hallucis } \\
\text { (oblique and } \\
\text { transverse } \\
\text { head) }\end{array}$ & $\begin{array}{l}\text { Oblique - } \\
\text { proximal } \\
\text { end of } \\
\text { metatarsals } \\
\text { two-four } \\
\text { Transverse } \\
\text { - via } \\
\text { metatarsal } \\
\text { phalangeal } \\
\text { ligaments of } \\
\text { digits three- } \\
\text { five }\end{array}$ & $\begin{array}{l}\text { Proximal } \\
\text { phalanx of } \\
\text { great toe }\end{array}$ & $\begin{array}{l}\text { Adduction of the } \\
\text { great toe }\end{array}$ & $\begin{array}{l}\text { First } \\
\text { plantar } \\
\text { metatarsal } \\
\text { artery }\end{array}$ & $\begin{array}{l}\text { Deep branch } \\
\text { of the lateral } \\
\text { plantar } \\
\text { nerve }\end{array}$ \\
\hline $\begin{array}{l}\text { Flexor Digiti } \\
\text { Minimi } \\
\text { Brevis }\end{array}$ & $\begin{array}{l}\text { Base of fifth } \\
\text { metatarsal }\end{array}$ & $\begin{array}{l}\text { Proximal } \\
\text { phalanx of } \\
\text { the fifth } \\
\text { metatarsal }\end{array}$ & $\begin{array}{l}\text { Flexion of the fifth } \\
\text { digit }\end{array}$ & $\begin{array}{l}\text { Lateral } \\
\text { plantar } \\
\text { artery }\end{array}$ & $\begin{array}{l}\text { Lateral } \\
\text { plantar } \\
\text { nerve }\end{array}$ \\
\hline
\end{tabular}




\begin{tabular}{|c|c|c|c|c|c|}
\hline $\begin{array}{l}\text { 4th Layer } \\
\text { Plantar } \\
\text { Interosseous }\end{array}$ & $\begin{array}{l}\text { Medial } \\
\text { aspect of } \\
\text { the } \\
\text { individual } \\
\text { metatarsals } \\
\text { of digits } \\
\text { three-five }\end{array}$ & $\begin{array}{l}\text { Proximal } \\
\text { phalanges }\end{array}$ & Adduction of digits & $\begin{array}{l}\text { Plantar } \\
\text { metatarsal } \\
\text { artery }\end{array}$ & $\begin{array}{l}\text { Lateral } \\
\text { plantar } \\
\text { nerve }\end{array}$ \\
\hline
\end{tabular}

Subsystems of the Foot

A subsystem is a division of the foot that provides ligamentous, muscular, or neural support. The subsystems of the foot are comprised of three sections: the active, the passive and the neural subsystems. Within the active subsystem there contains muscles and tendons that attach on the foot, which are also known as the extrinsic and intrinsic foot muscles (see Table B1-B3). The extrinsic muscles can be divided into compartments of the lower leg. These consist of the lateral compartment, anterior compartment, deep posterior compartment and superficial posterior compartment.3,4,7,8 The lateral compartment contains the fibularis longus and fibularis brevis muscles. The fibularis longus is especially important for stabilization occurring at the mid foot and first ray and will act as an evertor of the forefoot as well as a plantar flexor of the first ray.3,4,6,35 The fibularis brevis muscle will act to evert the midfoot and rearfoot.3,6 The anterior compartment consists of the fibularis tertius, tibialis anterior, extensor digitorum longus and extensor hallucis longus muscles. The fibularis tertius will act to evert the foot along with the lateral compartment muscles.3,6,7 The tibialis anterior helps to provide balance during the first quarter stance of gait and lift the toes at the terminal stances of gait.3,36 The extensor digitorum longus and extensor hallucis longus act in lifting the toes off the ground with the tibialis anterior during the late stages of gait and aid in stabilization of the talocrural joint.3,4,6,8 The deep posterior compartment is composed of the flexor hallucis longus, flexor digitorum longus, and 
tibialis posterior muscles. The flexor digitorum longus and flexor hallucis longus muscles have shown immense support isometrically for the longitudinal arches as well as afferent feedback and force dispersion during gait loading.3,6,35 The tibialis posterior supports the MLA by inserting onto the bones that create this arch. This muscle will resist eversion and aid in stabilizing the rearfoot during the gait phases of initial contact and midstance. 3,4 The superficial posterior compartment consists of the gastrocnemius, soleus, and plantaris muscles. The gastrocnemius and the soleus combine to form the triceps surae, which controls forward motions of the lower leg bones on the talus and can help to provide knee flexion.3,6,35 Due to the insertion on the calcaneus, the triceps surae act on the forefoot, midfoot and rearfoot. This occurs from the connection these muscles have to the plantar aponeurosis, or plantar fascia.3,4,6

The intrinsic muscles consist of ten plantar muscles that can be divided into specific layers on the foot (Table B2 and B3). The first layer consists of the abductor hallucis, flexor digitorum brevis, and the abductor digiti minimi.3,4,35 This layer abducts the hallux, provide flexion at toes two through five and when in the open chain abducts the fifth toe. The abductor hallucis and abductor digiti minimi stabilize the medial and lateral longitudinal arches during stance phases. 3,7 The second layer consists of the quadratus plantae, and the four lumbrical muscles. Within the open chain these muscles perform toe and metatarsophalangeal flexion as well as interphalangeal extension.3,7 During gait phases, the lumbricals provide eccentric control to metatarsophalangeal extension and extend the interphalangeal joints. The quadratus plantae allows for force changes due to the arrangement of the muscle near the flexor digitorum longus.3,35 The third plantar layer is comprised of the flexor digiti minimi, adductor hallucis, and flexor hallucis brevis muscles. Open kinetic chain will consist of these muscles performing fifth digit flexion, hallux adduction, and hallux flexion. During gait phases the adductor hallucis aids 
in stabilization of the first ray while flexor hallucis brevis and flexor digiti minimi eccentrically control extension of the toes.3,7,35 The fourth and final layer consists of the three plantar interossei muscles. These muscles act by adducting the toes during the open kinetic chain. During gait these muscles eccentrically control toe spreading during loading activities and preswing phases of gait.3,35

The passive subsystem is comprised of structures that provide stability to the foot without movement. The passive subsystem consists of the other anatomical structures present such as the plantar fascia, bones of the arches (medial longitudinal arch, lateral longitudinal arch, anterior transverse metatarsal arch, and posterior transverse metatarsal arch), and the ligaments. 3,5 According to Drake et al.36 the plantar fascia is known to be connective tissue that is thick and fibrous. The plantar fascia provides support to the longitudinal arch through dynamic shock absorption. 36 The bones of the arches include the seven tarsal bones, which are the calcaneus, talus, navicular, medial cuneiform, intermediate cuneiform, lateral cuneiform, and cuboid bones. Distal from the tarsal bones are the five metatarsal bones.6 These begin with the first metatarsal on the medial aspect of the foot going to the fifth metatarsal on the lateral aspect.6 The lateral longitudinal arch and medial longitudinal arch are in the sagittal plane from the rearfoot to the forefoot. The transverse arches are located on the coronal plane in the forefoot and are comprised of the five metatarsal heads. 30 Without proper alignment of bones, the joints of the foot would not be able to perform movement efficiently, the ligaments would become taut or tight and the whole system of the foot would be interrupted.3

Ligaments provide static support to the arches as well as the multiple joints of the foot. 6 The long and short plantar ligaments as well as the calcaneonavicular ligament are three ligaments that support the arches of the foot statically.3,5 The deltoid ligament, anterior 
talofibular ligament, calcaneofibular ligament, and posterior talofibular ligament help statically support the talocrural joint.3,6 The subtalar joint relies on the interosseous talocalcaneal, posterior talocalcaneal, lateral talocalcaneal, calcaneofibular, and fibular talocalcaneal ligaments for its static support. 3,5 The bifurcate, dorsal calcaneocuboid, dorsal talonavicular, interosseous talocalcaneal, deltoid, spring and plantar cuboideonavicular ligaments play a key role in statically supporting the transverse tarsal joint. $3,5,6$

The neural subsystems deal with the sensory receptors that are within the active and passive subsystems. The sensory receptors within the neural subsystems can be categorized into the musculotendinous receptors, ligamentous receptors and plantar cutaneous receptors.4,5The cutaneous feedback from the plantar aspect of the foot is crucial for the foot to allow and maintain proper balance and postural stability. With certain pressures applied to the plantar aspect of the foot, a change in sensory feedback may occur, such as an increase in afferent information. Afferent feedback is related to sensory neurons that carry specific impulses from stimuli to the central nervous system and brain. This specific feedback is then transferred to the efferent neurons that carry the impulses from the central nervous system to the specific muscles to cause a desired movement.4,5,37 In order to achieve balance and locomotion during activities, the activation of the most sensitive fast adapting receptors is necessary to transmit the afferent information.37 History of ankle sprains or injuries may decrease the sensitivity and feedback of the cutaneous afferent receptors. 37 Throughout the gait cycle, the plantar aspect of the foot is able to adapt and respond to different cutaneous stimuli due to plantar tactile sensitivity and the neuro-motor system. 38 When a loss of sensory input from the mechanoreceptors is demonstrated, a reduction of plantar tactile sensitivity will also be present. 37 During gait patterns, the sole of the foot detects external stimuli and incorporates neural feedback in order to achieve proper 
plantar tactile sensitivity to adapt to environments and perform all the gait cycles necessary. 38 The intrinsic muscles of the foot have proper anatomical positioning to allow for proper sensory feedback due to the stretch response. This stretch response will specifically occur through changes in foot dome posture on the plantar aspect of the foot. 4 With proper training of these sensory receptors, sensitivity can be altered for foot dome deformation. 4 When the intrinsic muscles are fatigued, an increase in foot pronation occurs. This is often attributed to the motor function of these intrinsic muscles, but the sensory aspect of these muscles should be considered as well. The change in sensory information occurs through fatiguing exercises that decrease joint position sense in areas of the lower extremity.4 Therefore, the neural subsystem of the foot consisting of the musculocutaneous receptors, ligamentous receptors and plantar cutaneous receptors act on the foot to allow for proper foot dome posture. 4

All three subsystems are activated during the mechanism of an ankle or foot injury. Damage may depend on severity of the injury itself, but it is important to understand each layer that comprises the foot, especially when deciding on rehabilitation techniques. The neurovascular structures of the foot are an important component due to innervations and blood supply branching in that area. Most of the innervations that occur in the foot first arise with the sciatic nerve. 35 The nerves of the foot consist of the superficial fibular nerve, deep fibular nerve, tibial nerve.6,35 The nerves that innervate the intrinsic muscles branch from the tibial nerve. 3 Innervation of the intrinsic muscles of the foot come from the deep fibular nerve, medial plantar nerve, and lateral plantar nerve.6,35 The blood supply for the foot starts with the popliteal artery of the lower leg.35 The foot is then supplied through the anterior tibial artery, fibular artery, sural artery, posterior tibial artery, dorsalis pedis artery, medial plantar artery, lateral plantar artery and 
first plantar metatarsal artery.35 The innervation and circulation provided to the foot are important for the plantar aspect, specifically the intrinsic muscles that assist in foot core.6,35 Biomechanics

Each aspect of the foot provides different attributes during the different stages of gait. The rearfoot starts in a position of plantar flexion, pronation and adduction during the early stages of gait.3 The rearfoot will then transition into dorsiflexion, pronation and abduction at the body moves into the midstance phase of gait.3 Once the foot is through $70 \%$ of the stance phase the rearfoot will then switch to plantar flexion and supination. These motions allow the rearfoot to complete the stages of gait. The midfoot is kept in a neutral position for most of the stance phase. During $15 \%-80 \%$ of the stance phase this neutral position is maintained within the midfoot, but when the last $20 \%$ occurs, the midfoot becomes plantarflexed, supinated and abducted.3 The rearfoot and the forefoot demonstrate a coupling effect that allows for positioning and control of the MLA.8 During mid to terminal stance phases, the tibia and fibula externally rotate while the rearfoot is brought into supination. This causes the talonavicular and calcaneocuboid axes to diverge, therefore creating a rigid lever for optimal push off to occur. 3 The lateral forefoot is in a dorsiflexed position, with slight supination, within $15 \%$ to $70 \%$ of the stance phase. During midstance, the medial forefoot then becomes more loaded making the force dispersion more equal within the foot.3 Supination of the lateral forefoot and increases in metatarsal arch height occur during $70 \%$ to $90 \%$ of the stance, which will then result in the forefoot tightening and preparing the foot for push off to occur. 3

Certain biomechanical aspects, such as push off, may be changed dependent on the load placed on the foot. During low load activities, the rearfoot is plantarflexed and adducted. The plantar pressures will then shift from the medial to the lateral forefoot, shortening the lever arm, 
therefore transmitting the push off from the lateral heel to the lateral aspect of the forefoot.3,5 During high load activities, the plantar fascia of the foot becomes taut and a closed pack position is formed through eversion of the fibularis longus. This action will then be coupled with the rearfoot and forefoot to avoid a break in the metatarsal area.3 Force is then transmitted through the hallux and first metatarsal head to allow push off to occur through the metatarsophalangeal axis.3,5 The foot core, or group of plantar intrinsic muscles that create a dome, then becomes important with biomechanical aspects, especially gait patterns, due to the role of intrinsic foot muscles in transmission of forces and stability of the MLA during phases of gait.5

The muscles located in and around the foot, also known as the intrinsic and extrinsic muscles, attribute to many factors of the foot. These muscles act together to maintain the height of the arches and decrease foot pronation, protect the plantar fascia, generate and absorb power and work with the transmission of ground reaction forces.5,17 The extrinsic and intrinsic muscles of the foot help to support the foot, stabilize the foot, perform force dispersion and move the multiple configurations of the ankle and foot.3 The extrinsic muscles act as the global movers of the foot.4,5 These muscles generate large movements and allow for absorption and propulsion during the gait phases.5

Within the lateral compartment of the foot, the fibularis longus helps to support the MLA as well as stabilize the medial column through eversion of the first ray and provide afferent feedback for foot and ankle positioning. 3 The fibularis brevis of the lateral compartment acts to evert the talocrural and subtalar joints as well as evert the rearfoot and midfoot. 3 The muscles of the anterior compartment play an important role in ankle kinesthesia and modulation of the soleus throughout the stance phases of gait through the use of afferent feedback.3 The muscles of the superficial posterior compartment of the lower leg act on the rearfoot, midfoot and forefoot 
due to the connection to the calcaneus and plantar fascia. When these muscles contract during weight bearing activities, tension of the plantar fascia is created through plantarflexion of the rearfoot, then further creating a dorsiflexed position. This transition further allows for ground force reaction within the foot.3 The deep posterior compartment of the lower leg provides stabilization and support for the arches of the foot through isometric contractions during the stance phases of gait. These muscles have also demonstrated afferent feedback and force dispersion during activities involving loading. 3

It is crucial for the foot to become a stable base for all activities, and the intrinsic muscles are the main source of that base stability. These muscles allow control of arch deformation velocity and degree allowing more stability by activating the MLA.4 Within the open kinetic chain, the intrinsic foot muscles act to shape the foot and toes to prepare for contact with the ground. During closed kinetic chain events, the intrinsic foot muscles act to provide force transmission and accommodate to a variety of terrain.3 The intrinsic muscles provide firmness and stability for the propulsive stages of gait while also providing flexibility for absorption of forces.16 One of the main biomechanical roles that the intrinsic muscles provide to the body is support of integrity of the MLA.16 Intrinsic muscles play a large role in sensory information due to the stretch response for foot posture. The locations and actions of these muscles help with gait patterns, need for support of the arches, adapt to high demand of activities, and high demand of load placed on structures.4 These specific muscles have a direct correlation to the stress placed on the plantar fascia. When the intrinsic muscles are weakened there may be an increase in load on the plantar fascia, therefore increasing the likelihood of plantar fasciitis to occur in an individual.8,39

Ice Hockey 
Ice hockey is a sport that requires specific biomechanical techniques to perform the sport correctly. It is a sport that is fast and dynamic, requiring an immense amount of stability.33 As with any sport that uses skating as a form of propulsion, the maintenance of balance and stability on a very narrow base of support, such as the blade on a skate is imperative. This narrow base of support limits the athlete's biomechanical stability.12,33 In order to balance over such a small blade, the utilization of eccentric muscle control and proprioceptive skills are necessary.12 Ice hockey athletes are required to skate on a small balance point, forwards, backwards and sideways. At times, the eccentric muscle control and proprioceptive skills may become strenuous for the ice hockey player because of the constant need for stability on such a limited base of support. Therefore, intrinsic foot muscles may become fatigued due to overwork and stress. Thus, strains of the intrinsic muscles of the foot are commonly seen in ice hockey athletes due to a fatiguing effect.12 Although it is difficult to relate gait patterns to ice hockey, as athletes are in skates and glide rather than walk or run, ice hockey players still utilize plantar force application. Through utilization of the plantar aspect of the foot, ice hockey players are able to perform propulsion. Ice hockey athletes often perform plantar force application by dispersing the forces from the foot through utilization of plantar pressure.13 An important aspect of skating in ice hockey is to push off with the toes for proper propulsion in the stride. Therefore, dispersion of forces throughout the foot are a crucial aspect of hockey that may be overlooked.13

As with walking, skating is a biphasic movement that requires single and double-limb support. Within the sport of ice hockey forward and backward skating as well as multidirectional changes are required in order to be successful at the game.12 To compare ice skating to walking is easiest when comparing the support phase of walking with the skating glide. However, the slick surface of ice skating decreases the anterior linear shear forces during late midstance to 
propulsion phases and posterior linear shear forces within the touchdown phase due to the decrease of friction of the surface. 12 With walking, the center of gravity is typically in a linear path over the foot, but with ice hockey, the requirement of foot abduction and hip external rotation due to the lack of friction will cause the center of gravity to shift in an opposite direction to the weight bearing skate.12 A common biomechanical aspect of ice hockey is acceleration. Acceleration occurs within the first three strides of skating creating a glide phase. A different skating pattern will develop during the fourth stride, which is typically called the skate cut.12 This is a combination of negative and positive acceleration incorporating three different phases. First, negative acceleration takes place through single limb glide. The single limb will then act through propulsion as well as externally rotating the thigh and extending the hip and knee. Lastly, the other limb will complete the propulsion by initiating full knee extension, hip hyperextension, and ankle plantar flexion.12

The importance of balance is typically overlooked when it comes to ice hockey athletes. In fact, balance is one of the crucial factors in ice hockey.33 In order to acquire the correct skating techniques and stability on the ice, an intricate level of balance is required.33 When an ice hockey player is skating, the amount of time spent on the lateral edge of the skate impacts power and efficiency acquired while skating. Therefore, when an ice hockey athlete falls into foot pronation, spending more time on the medial edge of the skate decreases power and efficiency in performance. 12

Rehabilitation Programs: Traditional Rehabilitation

There are many traditional rehabilitation exercises that are used for ankle and foot injuries. These consist of exercises utilized for ankle or foot injuries that do not isolate the foot core or intrinsic muscles, but rather the extrinsic muscles. Towel curls and marble pick-ups are 
just two examples of traditional rehabilitation exercises utilized by many clinicians. The exercises aforementioned mainly incorporate the extrinsic muscles. 4 The towel curl exercise consists of the patient laying a towel on a slick surface and dragging the towel with the toes on the edge of the towel.16 The towel curl exercise demonstrated a significant increase in the navicular drop test while the towel curl exercise performed in maximum plantar flexion demonstrated a decrease in the navicular drop test.40 Therefore, the towel curl exercise may be beneficial in working to support the MLA in subjects.40 The study performed by Lynn et al.16 demonstrated that the towel curl exercise was not as beneficial as the short foot exercise in training the intrinsic foot muscle groups. Mulligan and Cook7 discussed a study that compared towel curl exercises to short foot exercises of the foot. It was found that navicular height, or arch height, was not different between the groups post-training. However, the range of movement in the non-dominant limbs center of pressure during a modified SEBT was smaller for the short foot exercise group. 7,16

Towel curls and marble or foam pick up exercises are toe curling exercises that recruit more than just the intrinsic muscles of the feet. These exercises will recruit extrinsic muscles that are long toe flexors such as the flexor hallucis longus and flexor digitorum longus muscles.4,7,41 Recruitment of toe flexors during these exercises of towel curls and marble pick-ups is not an effective way to strengthen the intrinsic muscles and assist the MLA.41 During the towel curl exercise, activation of some of the intrinsic muscles, such as abductor hallucis, is over four times less when compared to foot core exercises for seated and single-legged standing positions.4 It was also demonstrated that when compared to towel curling exercises, the short foot exercises showed greater increases in dynamic balance. 4 Without isolation of the intrinsic muscles it is 
difficult for the rehabilitation exercises to have the same benefits as when just the intrinsic muscles are isolated.4

Hall et al.42 discussed a study that involved the use of resistance band exercises and proprioceptive neuromuscular facilitation (PNF). These exercises focused on chronic ankle instability and demonstrated improvements in stability and strength for participants. Although improvements were evident in measures of ankle strength, there were no benefits for levels of balance and functional movements. Within this study the participants balance levels were tested using the figure- 8 hop test, triple crossover hop test and the $\mathrm{Y}$ balance test. Hall et al.42 and McKeon et al.4 both showed utilization of the extrinsic muscles instead of targeting solely the intrinsic group. However, both methods of rehabilitation did show benefits for the patient, regardless of whether the intrinsic muscle group were used. 4,42

Some traditional methods have an immense increase in benefits for athletes with ankle injuries. These include balance training, impairment based progressive rehabilitation programs and functional rehabilitation. Within some balance training rehabilitation protocols, the patient goes through a home exercise program that has shown improvements in postural control and stability in both the affected and unaffected limb.4,43 Hale et al.43 studied 34 participants in a cohort study examining the effects of balance training on chronic ankle instability. Hale et al.43 found that training the uninjured ankle may be a beneficial aspect to rehabilitation programs, showing increases in balance and function in the injured ankle. Hale et al.43 demonstrated better scores for patient reported outcome measures as well as the star excursion balance test in the rehabilitation group who performed unilateral balance training.

Rehabilitation Programs: Foot Core Exercises 
McKeon et al.4 discussed the impact of the intrinsic foot muscle test, or short foot exercises, on the ankle and foot. In order to perform the short foot exercise, the patient must be able to maintain a subtalar neutral position while standing on one leg.4 The importance of the patient understanding when in subtalar neutral and correctly activating the intrinsic muscles by lifting the arch is imperative. If the patient understands these aspects, then it will be easier for replication and for the patient to perform this exercise at home.4 These exercises are performed in progression. The progression of this exercise can go from seated, standing, standing on one leg, and then with functional activities such as squatting and jumping.4

The benefits of the short foot exercise make it a key aspect of rehabilitation for ankle and foot injuries. McKeon et al.4 discussed these benefits such as improved balance and foot function. With balance and function being two crucial factors for rehabilitation of the foot and ankle, the short foot exercise would be extremely beneficial for an ankle or foot rehabilitation program.4 A reduction in arch collapse, or decrease in foot pronation, was also found with the use of the short foot exercise, which allowed for an increase in support for the foot and the ankle.4,29 The short foot exercise also demonstrated the ability to correct foot alignment in patients.29 Mulligan and Cook7 demonstrated that the short foot exercise allowed for greater support of the MLA both statically and dynamically. The study performed by Headlee et al.44 demonstrated that an increase in fatigue in the intrinsic foot muscles leads to an increase in pronation of the foot by measurement of navicular drop. This direct correlation was shown by taking 21 healthy participants and taking navicular drop measurements before and after fatiguing the intrinsic muscles by performing isotonic exercises. 44 The short foot exercise may also be beneficial for patients with chronic ankle instability and pes planus. McKeon et al.4 showed that the use of the short foot exercise could improve function for patients with chronic ankle 
instability and increase great toe flexion and cross-sectional area of the abductor hallucis muscle in patients with pes planus.4

For the patients with pes planus, there is a high risk for plantar fasciitis and ankle injuries due to their anatomical structure, making the short foot exercise a method to avoid future injury.4 As stated previously, Drake et al.36 discussed the prevalence of plantar fasciitis in the human population. 36 The prevalence shown by this study can then be combined with the Cheung et al.45 study that utilized 20 experienced runners to demonstrate the relationship between the volume of intrinsic foot muscles and the occurrence of plantar fasciitis. 45 The findings of Cheung et al.'s 45 study helped to describe how participants dealt with chronic plantar fasciitis by demonstrating a decrease in intrinsic muscle volume compared to healthy participants. From this information, the study then goes on to recommend intrinsic muscle strengthening for those suffering from plantar fasciitis. 45

There is a plethora of intrinsic muscles located in the plantar surface of the foot. Thus, there are different exercises to target different intrinsic muscles. Although all exercises target the intrinsic muscles to some extent, Gooding et al.10 utilized T2 magnetic resonance imaging on track and field and cross country athletes to demonstrate the different exercises and what intrinsic muscles are primarily targeted. The short foot exercise as discussed previously is performed through drawing the metatarsal heads towards the calcaneus by raising the MLA. This should be performed with no flexion of the toes or extrinsic muscle involvement present and should be held in an isometric contraction. This exercise demonstrated primary activation of the abductor digiti minimi and abductor hallucis muscles.10 The toes spread out exercises is described by extension of all five toes. During this the simultaneous performance of abduction of all five toes while also performing flexion of just the first and fifth toes to the floor occurs. The 
second to fourth toes are kept in extension. The toes spread out exercise primarily activated the abductor digiti minimi and the adductor hallucis oblique muscles.10 The first toe extension exercise was simply performed through extension of the first toe while keeping the second to fifth toes neutrally on the ground. This exercise primarily activated the flexor digitorum brevis and the abductor hallucis muscles. Finally, the second to fifth toe extension exercise was performed by extending the second, third, fourth and fifth toes while the first toe remained on the ground. This exercise demonstrated a primary activation of the abductor digiti minimi and the flexor hallucis brevis muscles.10 Gooding et al.10 discussed how each of these exercises activate the intrinsic foot muscles to some degree and each exercise can result in a $9 \%$ to $35 \%$ increase in intrinsic foot muscle activation.

Other methods of targeting intrinsic muscle activation are available as well. One method includes utilizing minimalist shoes for running athletes. Some see this as reduction in support for the foot, but according to Miller et al.39, it is stated that wearing minimalist shoes while running may actually increase the strength of the intrinsic foot muscles.39 The study performed by Miller et al.39 consisted of 33 healthy runners randomized into control and experimental groups. Both groups within the study received MRI scanning before and after the 12-week training period. Each group also underwent testing of running kinematics, arch stiffness and height before and after the training period. From there, cross sectional areas and muscle volumes were assessed.39 Miller et al.39 found that most current shoes include structures that decrease the incorporation of the intrinsic foot muscles during gait. With the use of minimalist shoes, there is a substantial reliance on the arch of the foot to be the base of support. 39 With the arch being the base of support, the spring like characteristics are then utilized and a more rigid arch is developed. Miller et al.39 goes on to describe that the more the arch is activated with wearing minimalist shoes the 
higher the function and strengthening of the surrounding muscles, with emphasis on the intrinsic muscle group. Although this is seen as a beneficial method of increasing the function of the intrinsic muscle group, the patient must be aware to perform this as a gradual progression in a careful manner.39

Functional Rehabilitation to Improve Stability and Strength

The impairment based progressive rehabilitation program focused on increasing range of motion, strength, balance, functional movements and self-reported measures.46 In order to increase range of motion the program utilized joint mobilizations. Strength is focused on through the use of heel raises, forefoot raises, 4-way manual ankle resistance, PNF, 4-way walks and short foot exercise. For balance the program works on eyes open and eyes closed static balance, reaching tasks and hop to stabilization all used with and without instability tools. Restoring function is something that all rehabilitation programs should focus on for the patient to feel comfortable and confident that the injury is healed properly. This program performs lunges, stepups, step-downs, dot drill jumps, cutting, and treadmill walking to address function.46 The study performed by Donovan et al.46 showed an increase in all measures of range of motion, strength, balance, functional movements and self-reported measures by using this impairment based progressive rehabilitation program for ankle injuries.

The functional rehabilitation method places an emphasis on similar topics as the ones listed previously. Range of motion, static balance, dynamic balance, strength, plyometrics, and speed and agility are all categories focused on throughout the study performed by Kim and So.47 For this ankle rehabilitation, range of motion is increased through the use of Achilles stretching and active range of motion through writing the alphabet letters in the air with the foot. Single leg squats and ball catching in the single leg squat position are used for static balance while single 
leg lunges using a balance pad or box are utilized for dynamic balance. Single leg heel raises, bridges, dorsiflexion and eversion while using a band are used to increase strength in the patient. Plyometric abilities are increased with the use of jumping on spot exercises and hurdles while speed and agility utilize forward and lateral ladder drills. The study performed by Kim and So 47 analyzing functional rehabilitation demonstrated improvements in the Cumberland ankle instability tool, stability, gait analysis, isokinetic strength and motion analysis measurements. Kim and So47 established that this functional rehabilitation is beneficial for chronic ankle instability patients, however the exclusion of a control group created a limitation to this study. The functional rehabilitation method examined by Kim and So47 lacked the inclusion of the intrinsic foot muscles. This allows a strengthening component to the rehabilitation program by incorporating intrinsic muscle. 47

Measurement Techniques

In order to determine the benefits of specific exercises, it is important to know proper measurement techniques. To measure the height of the MLA, a navicular drop test is typically utilized, which can demonstrate fatigue or weakness in any of the muscles that support the MLA.31 The navicular drop test measures pronation of the foot through measurement of the navicular tuberosity height.44 This will determine the difference of the navicular tuberosity of the patient from the seated position to the standing position. 7 The navicular drop test demonstrated being a reproducible, valid and simple test in regard to determining MLA height, that was accompanied with minimal disadvantages.18 Intraclass correlation coefficients were shown to be greater than .880 for the navicular drop test, demonstrating excellent reliability.18 The navicular drop test demonstrates an intra- and inter-day repeatability of $1.1 \mathrm{~mm}$ and $2.3 \mathrm{~mm}$, which also correlates to an intercorrelation coefficient of .97 and .87.19 Through measurement of the 
navicular drop test, strong intratester reliability as well as precision is demonstrated for measuring intrinsic foot muscle fatigue. 44

To measure balance, the "Y" balance test or star excursion balance test is often utilized. This is performed in single leg standing position and the patient will proceed to reach their leg in the anterior, posteromedial and posterolateral directions. Those distances will be measured and can be compared to the patient's leg length to determine abnormalities.7,16 The Star Excursion Balance Test has demonstrated reliable results in testing dynamic postural control or balance in the anterior, posteromedial and posterolateral directions.27 The SEBT demonstrates excellent inter and intra-rater reliability, minimal detectable change, associations with increase injury risk, and convergent validity.24-26 This dynamic balance test is shown to be a reliable and valid test that examines postural stability.27 Kinzey and Armstrong23 found an intraclass correlation coefficient (ICC) of .86 to .98 , demonstrating moderate reliability for the SEBT in assessing dynamic balance while Lynn et al.16 found an ICC of .67 to .87 demonstrating good reliability of the "Y" balance test, or SEBT. Mulligan and Cook7 also found that the SEBT had an ICC of .87 for anterior reach, .87 for posteromedial reach, and .86 for posterolateral reach demonstrating good reliability for all directions.

Summary

The foot is composed of numerous anatomical structures that perform of a multitude of functional tasks for the body.2 The configuration of the foot is made up of bones, ligaments, and muscles, which then further create the four arches of the foot.2,4,6 All of these structures can be divided into subsystems; active, passive, and neural.4,5 Throughout the complex structure of the foot, stabilization is primarily performed through the intrinsic muscles, which originate and insert on the plantar and dorsal aspects of the foot.2 The intrinsic muscles help to provide a stable 
base as well as provide support to the MLA by keeping the integrity of the arches and decreasing the risk for foot pronation.4,5 Ice hockey is a sport that requires an immense amount of stability over a small base of support. A fatiguing effect of the intrinsic muscles is often seen in ice hockey players. When specifically looking at agility, performance is most optimal when skaters are on the lateral edge of the skate or lifting of the arch to avoid foot pronation is present.12,33 There are exercises for rehabilitation of the foot and ankle. These consist of exercises solely focused on the foot core; short foot, toes spread out, first toe extension and second to fifth toe extension.10 There are also exercises that target both intrinsic and extrinsic muscles, such as marble pickups and towel curls.4,16. Other exercises consist of functional rehabilitation exercises that incorporate balance, strength, range of motion, plyometrics, speed and agility.46,47 In order to measure and determine effects on navicular position and balance it is important to utilize navicular drop test and star excursion balance test. These tests are shown to be reliable and valid tests in order to determine navicular position within the foot in relation to arch height and intrinsic foot muscle fatigue as well as dynamic balance ability and postural control.18,48 


\section{APPENDIX C}

\section{ADDITIONAL METHODS}

\section{Key Information for: Effect of Foot Core Strengthening on Balance, Foot Position and Agility in Ice Hockey Players}

You are being asked to participate in the research described below. This page provides key information that may help you to make this decision; more detailed information can be found after this section.

Why is this research being done and what is involved?

In this section, briefly describe (in lay terms):

- The purpose of this study is to determine the effect of strengthening of intrinsic foot muscles on balance, foot position, and agility in ice hockey players.

- You will be placed in one of the two intervention groups where you will be taken through a 4-week exercise protocol. You will be completing an arch height measurement, balance test, agility drill, and a questionnaire as well.

- This research study will take 4-weeks for you to complete. Each exercise session will take 15-20 minutes to complete, the arch height measurement will take 5-10 minutes to complete, the balance test will take 5-10 minutes to complete, the agility test will take approximately 5 minutes to complete and the questionnaire will take 5-10 minutes to complete.

Do I have to participate and what are the risks involved?

Participation in this research study is completely voluntary and you are free to withdraw from the research at any time. If you do not wish to participate, please discuss alternatives with the researcher or refer to the "Alternatives" section in the consent form. You may or may not directly benefit from participating in this research.

Risks from participation in this study include fatigue of foot muscles due to exercises but that will go away.

\section{Who can I talk to if I have questions or concerns?}

If you have any questions or concerns about this research or would want to withdrawal from the study, you can contact Rebecca Veltrie at (845)-532-1554 or Michelle Sandrey at (304)-2930870 from the Dept. of Physical Activity and Sport Sciences at West Virginia University.

\section{For more information, please see the Informed Consent Form}




\title{
Informed Consent for Research $\mid$ Minimal Risk
}

\author{
Principal Investigator (PI) | \\ Michelle Sandrey, $\mathrm{PhD}$, ATC \\ Department \\ Physical Activity and Sport Sciences \\ Co-Investigator(s) \\ Rebecca Veltrie, ATC \\ Sponsor or Funding Source $\quad$ None \\ WVU IRB Protocol \# | \\ 1912821991 \\ Study Title \\ The Effect of Intrinsic Muscle Strengthening on Foot \\ Posture, Balance, and Agility in Ice Hockey Players
}

\section{Introduction}

You, , have been asked to participate in this research study,

which has been explained to you by This study is being conducted by Michelle Sandrey, PhD, ATC in the Department of Athletic Training at West Virginia University, along with Rebecca Veltrie, ATC. This research is being conducted to fulfill the requirements for a Master's degree in Athletic Training from the Department of Physical Activity and Sport Sciences at West Virginia University. This research is being conducted under the supervision of Michelle Sandrey, PhD, ATC.

\section{Purpose}

The purpose of this study is to determine the effects of strengthening the intrinsic foot muscles on balance, foot position and agility in ice hockey players. WVU expects to enroll approximately 45 subjects.

\section{Description of Procedures}

Each subject will go through pre and post testing. This study involves measurement of your navicular drop or arch height differences from seated to standing with the use of a tape measure utilizing millimeters, which will take approximately 5-10 minutes to complete. You will then be taken through the Star Excursion Balance Test which consists of you standing on one leg while reaching your other leg out in front of you, back behind you to the left and back behind you to the right as far as you can reach. This will all be measured for distance based on your average of 3 trials for each direction and will take approximately 5-10 minutes to complete. You will then be given a questionnaire to complete, the foot and ankle ability measure (FAAM). This questionnaire will take approximately 5-10 minutes to complete. On a separate day, the subject will be taken through a timed agility test called the S-Cornering drill where the subject will start behind the goal, go around the first face-off circle, and then the subject will skate around the other face-off circle ending at the first blue line. You will then be put into one of the two intervention groups. Each group will meet twice a week for approximately 15 minutes for a 4week period.

The foot core intervention group will perform "short foot" exercises and "toe-spread-out" exercises. Short foot is performed by having your foot in a neutral position on the ground and 
raising the arch of your foot without using the larger muscles of the lower leg at all. This will be performed for a total of 3 sets of 5 with ten second holds. This will be progressed from the seated position, to standing and then to standing on one leg. This will be performed bilaterally and simultaneously. The toes-spread-out exercise will be performed in the seated position and you will extend all of your toes, then fan out all of your toes, and finally flex the first and fifth toe to the floor while keeping the second to fourth toes in the air. This will be completed for 3 sets of 10 . This will be progressed by the first week only extending and fanning out the toes, the second week you will fan out and then flex the big toe to the floor and the third and fourth weeks you will fan out the toes, flex the big toe and pinky toe to the ground while keeping the other toes extended. This will be performed bilaterally and simultaneously. These two foot core exercises will take approximately 15 minutes.

The traditional intervention group will go through towel curl exercises and foam pick up exercises. The towel curl exercise will be performed in the seated position with your toes at the edge of a towel. You will then drag the towel with your toes by curling or flexing them. You will drag the entire towel for a total of 3 times and each grip will be held for 5 seconds. This will be performed bilaterally and simultaneously. The foam pick up exercises will consist of you seated in a chair picking up pieces of foam with your toes and placing them into a container. You will fill the container for a total of 3 sets. This will be performed bilaterally alternating feet. These two traditional exercises will take approximately 15 minutes.

This will take approximately 4 weeks for the completion of your participation of this research study. Each subject will complete the exercises 2 days a week for 4 weeks.

\section{Risks and Discomforts}

There may be mild frustration associated with answering the questionnaire as well as attempting to perform some of the exercises. You may feel slight fatigue or discomfort during or after the exercises within this study, but this will go away. If at any point during the procedures you begin to feel pain, please indicate this to the investigator. If this occurs, the testing will be suspended immediately and may be rescheduled to a later date once the pain is resolved.

In addition, there is always the risk of uncommon or previously unknown side effect(s) or event.

\section{Alternatives}

The alternative is to not participate in this study.

\section{Benefits}

You may or may not directly benefit from participating in this research. The knowledge gained from this study may eventually benefit others.

\section{Financial Considerations}

There will be no payments made for participation in this study. There is no cost to participants in this study.

\section{Confidentiality}

Any information about you that is obtained as a result of your participation in this research will be kept as confidential as legally possible. Your research records and test results, just like 
hospital records, may be subpoenaed by court order or may be inspected by the study sponsor or federal regulatory authorities without your additional consent.

You will be randomly assigned a four-digit ID number. This will allow the investigator to maintain confidentiality by not using your name during data collection. Also, all documents, forms and data collection sheets will be kept in a locked file cabinet in the athletic training research lab that can only be accessed by the investigators.

In any publications that result from this research, neither your name nor any information from which you might be identified will be published without your consent.

\section{HIPAA Authorization}

We know that information about your health is private. We are dedicated to protecting the privacy of that information. Because of this promise, we must get your written authorization (permission) before we may use or disclose your protected health information or share it with others.

You can decide to sign or not to sign this authorization section. However, if you choose not to sign this authorization, you will not be able to take part in the research study. Whatever choice you make about this research study will not have an effect on your access to medical care.

\section{Persons/Organizations Providing the Information}

Subjects that attend WVU and are part of the men's club ice hockey team.

\section{Persons/Organizations Receiving the Information}

- The research site(s) carrying out this study includes WVU

- Health care providers who provide services to you as part of this research study: Michelle A. Sandrey, PhD, ATC and Rebecca Veltrie, ATC.

- Laboratories and other people and groups that look into your health information as part of this study in agreement with the study protocol.

- The United State Department of Health and Human Services (which includes the National Institutes of Health (NIH), Food and Drug Administration (FDA)) and other groups that have the right to use the information as required by law.

- The members and staff of any institutional review board that oversees this research study.

- The West Virginia University Office of Human Research Protection and the West Virginia University Office of Sponsored Programs.

\section{The Following Information Will Be Used}

Information from your existing medical records, and new information about you that is created or collected during this study, such as: history and physicals, demographics data, and study forms for navicular drop height, Star Excursion Balance Test, ice hockey S-Cornering agility drill and FAAM questionnaire for both ADL and sport.

\section{The Information is Being Disclosed for the Following Reasons}


- Review of your data for quality assurance purposes

- Publication of study results (without identifying you)

- Other research purposes such as reviewing the safety or effectiveness of the study drug and other products or therapies; conducting performance reviews of the study drug; evaluating other products or therapies for patients; developing a better understanding of disease; improving the design of future clinical trials.

\section{You may Cancel this Authorization at Any Time by Writing to the Principal Investigator}

\section{Michelle A. Sandrey, PhD, ATC, PO Box 6116, West Virginia University, Morgantown, WV} 26506-6116

If you cancel this authorization, any information that was collected already for this study cannot be withdrawn. Once information is disclosed, according to this authorization, the recipient may re-disclose it and then the information may no longer be protected by federal regulations.

You have a right to see and make copies of your medical records. You will not be able to see or copy your records related to the study until the sponsor has completed all work related to the study. At that time, you may ask to see the study files related to your participation in the study and have the study researcher correct any information about you that is wrong.

This authorization will expire at the end of the study unless you cancel it before that time

\section{Voluntary Participation}

Participation in this study is voluntary. You are free to withdraw your consent to participate in this study at any time. Refusal to participate or withdrawal will not affect your class standing and participation in activities at WVU for the ice hockey team and will involve no penalty to you. If an injury occurs during the study, Rebecca Veltrie, ATC, will provide the necessary first aid and referral if necessary, as a certified health care professional. I understand that there will be no cost to me for any study related injuries as the medical athletic training services of the ATC are a service provided to the student-athletes on the ice hockey team.

In the event new information becomes available that may affect your willingness to participate in this study, this information will be given to you so that you can make an informed decision about whether or not to continue your participation.

\section{Contact Persons}

If you have any questions, concerns, or complaints about this research, you can contact Rebecca Veltrie, ATC at (845)-532-1554.

If you are hurt from being in this research, you should contact Michelle Sandrey at (304)-2930870. If injury occurs outside of business hours and is related to your participation in this research, please contact Rebecca Veltrie at 845-532-1554.

For information regarding your rights as a participant in research or to talk about the research, contact the WVU Office of Human Research Protection (OHRP) at (304) 293-7073 or by email at IRB@mail.wvu.edu. 


\section{Signatures and Authorization}

You have been given the opportunity to ask questions about the research and your authorization of HIPAA, and you have received answers concerning areas you did not understand. Upon signing this form, you will receive a copy.

\section{Participant Signature}

I willingly consent to participate in this research.

Signature of Subject or Subject's Legal Representative

Printed Name $\quad$ Date

\section{Consenting Individual Signature}

The participant has had the opportunity to have questions addressed. The participant willingly agrees to be in the study.

\footnotetext{
Signature of Person Obtaining Informed Consent
}

Printed Name

Date 


\begin{tabular}{|l|}
\hline Subject Number: \\
\hline Subject Age: $\quad$ Subject Height: \\
\hline Years Playing Hockey: \\
\hline
\end{tabular}

1. Have you had an injury to your quadricep muscles within the past six months? Yes/No If yes, please explain:

2. Have you had an injury to your hamstring muscles within the past six months? Yes/No If yes, please explain:

4. Have you had an injury to your hip flexor muscles within the past six months? Yes/No If yes, please explain:

5. Have you had an injury to your knees within the past six months? Yes/No If yes, please explain:

6. Have you had an injury to your ankles within the past six months? Yes/No If yes, please explain:

7. Have you had an injury to your feet within the past six months? Yes/No If yes, please explain:

3. Have you worn inserts or insoles in your shoes within the past six months? Yes/No If yes, please explain:

8. Have you taken any medications in the past six months? Yes/No If yes, please explain:

9. Have you had surgery on your lower extremity (i.e. below the hips) within the past six months? Yes/No

If yes, please explain:

10. Have you ever had a problem with balance or had an injury that affected your balance (i.e. concussion) within the past six months? Yes/No If yes, please explain: 
Foot and Ankle Ability Measure (FAAM)

Please answer every question with one response that most closely describes to your condition within the past week. If the activity in question is limited by something other than your foot or ankle mark not applicable (N/A).

\begin{tabular}{|c|c|c|c|c|c|c|c|}
\hline & Side & $\begin{array}{c}\text { No } \\
\text { difficulty }\end{array}$ & $\begin{array}{c}\text { Slight } \\
\text { Difficulty }\end{array}$ & $\begin{array}{l}\text { Moderate } \\
\text { Difficulty }\end{array}$ & $\begin{array}{l}\text { Extreme } \\
\text { Difficulty }\end{array}$ & $\begin{array}{c}\text { Unable } \\
\text { to do }\end{array}$ & $\mathrm{N} / \mathrm{A}$ \\
\hline \multirow[t]{2}{*}{ Standing } & Right & प & प & प & Q & प & प \\
\hline & Left & Q & ( & Q & ( & ૫ & Q \\
\hline \multirow[t]{2}{*}{$\begin{array}{l}\text { Walking on Even } \\
\text { Ground }\end{array}$} & Right & Q & Q & Q & Q & Q & Q \\
\hline & Left & Q & Q & Q & Q & Q & Q \\
\hline \multirow[t]{2}{*}{$\begin{array}{l}\text { Walking on even } \\
\text { ground without shoes }\end{array}$} & Right & Q & Q & Q & Q & Q & Q \\
\hline & Left & Q & ( & Q & Q & Q & Q \\
\hline \multirow[t]{2}{*}{ Walking up hills } & Right & Q & 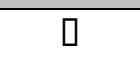 & 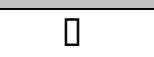 & $\square$ & 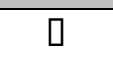 & Q \\
\hline & Left & Q & Q & Q & Q & Q & Q \\
\hline \multirow[t]{2}{*}{ Walking down hills } & Right & ( & प & प & प & प & Q \\
\hline & Left & Q & ( & Q & Q & Q & प \\
\hline \multirow[t]{2}{*}{ Going up stairs } & Right & Q & Q & Q & प & प & Q \\
\hline & Left & Q & Q & ૫ & Q & Q & Q \\
\hline \multirow[t]{2}{*}{ Going down stairs } & Right & Q & $\overline{0}$ & Q & Q & Q & 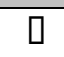 \\
\hline & Left & Q & Q & Q & Q & Q & ( \\
\hline \multirow{2}{*}{$\begin{array}{l}\text { Walking on uneven } \\
\text { ground }\end{array}$} & Right & Q & Q & Q & Q & Q & Q \\
\hline & Left & Q & ( & Q & Q & प & प \\
\hline \multirow[t]{2}{*}{$\begin{array}{l}\text { Stepping up and } \\
\text { down curbs }\end{array}$} & Right & Q & Q & Q & Q & Q & Q \\
\hline & Left & Q & Q & प & Q & Q & 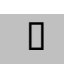 \\
\hline \multirow[t]{2}{*}{ Squatting } & Right & Q & प & Q & Q & प & Q \\
\hline & Left & Q & ( & ( & Q & ( & प \\
\hline \multirow[t]{2}{*}{$\begin{array}{l}\text { Coming up on your } \\
\text { toes }\end{array}$} & Right & ( & ( & Q & Q & Q & Q \\
\hline & Left & Q & Q & Q & Q & Q & Q \\
\hline \multirow[t]{2}{*}{ Walking initially } & Right & प & प & Q & प & प & Q \\
\hline & Left & प & Q & Q & Q & Q & Q \\
\hline \multirow[t]{2}{*}{$\begin{array}{l}\text { Walking } 5 \text { minutes or } \\
\text { less }\end{array}$} & Right & Q & 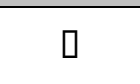 & Q & Q & Q & Q \\
\hline & Left & Q & Q & Q & Q & Q & Q \\
\hline \multirow{2}{*}{$\begin{array}{l}\text { Walking } \\
\text { approximately } 10 \\
\text { minutes }\end{array}$} & Right & प & प & प & प & प & 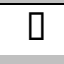 \\
\hline & Left & Q & Q & Q & Q & Q & Q \\
\hline \multirow[t]{2}{*}{$\begin{array}{l}\text { Walking } 15 \text { minutes } \\
\text { or greater }\end{array}$} & Right & Q & Q & $\square$ & $\square$ & Q & Q \\
\hline & Left & Q & ( & $\square$ & Q & Q & Q \\
\hline
\end{tabular}


Because of your foot and ankle how much difficulty do you have with:

\begin{tabular}{lllccccc}
\hline Standing & Side & $\begin{array}{c}\text { No } \\
\text { difficulty }\end{array}$ & $\begin{array}{c}\text { Slight } \\
\text { Difficulty }\end{array}$ & $\begin{array}{c}\text { Moderate } \\
\text { Difficulty }\end{array}$ & $\begin{array}{c}\text { Extreme } \\
\text { Difficulty }\end{array}$ & $\begin{array}{c}\text { Unable } \\
\text { to do }\end{array}$ & N/A \\
\hline Home responsibilities & Right & $\square$ & $\square$ & $\square$ & $\square$ & $\square$ & $\square$ \\
& Left & $\square$ & $\square$ & $\square$ & $\square$ & $\square$ & $\square$ \\
\hline Activities of daily living & Right & $\square$ & $\square$ & $\square$ & $\square$ & $\square$ & $\square$ \\
& Left & $\square$ & $\square$ & $\square$ & $\square$ & $\square$ & $\square$ \\
\hline Personal Care & Right & $\square$ & $\square$ & $\square$ & $\square$ & $\square$ & $\square$ \\
\hline $\begin{array}{l}\text { Light to moderate work } \\
\text { (standing, walking) }\end{array}$ & Left & $\square$ & $\square$ & $\square$ & $\square$ & $\square$ & $\square$ \\
\hline $\begin{array}{l}\text { Heavy work } \\
\text { (push/pulling, } \\
\text { climbing, carrying) }\end{array}$ & Left & $\square$ & $\square$ & $\square$ & $\square$ & $\square$ & $\square$ \\
\hline Recreational activities & Right & $\square$ & $\square$ & $\square$ & $\square$ & $\square$ & $\square$ \\
& Reft & $\square$ & $\square$ & $\square$ & $\square$ & $\square$ & $\square$ \\
\hline
\end{tabular}

How would you rate your current level of function during your usual activities of daily living from 0 to 100 with 100 being your level of function prior to your foot or ankle problem and 0 being the inability to perform any of your usual daily activities?

\section{Right: $\quad .0 \%$ Left: $\quad .0 \%$}

Total FAAM ADL Score: Right: Left:

(Clinicians Only) 
FAAM Sports Scale

Because of your foot and ankle how much difficulty do you have with:

\begin{tabular}{llllcccc}
\hline & Side & $\begin{array}{c}\text { No } \\
\text { difficulty }\end{array}$ & $\begin{array}{c}\text { Slight } \\
\text { Difficulty }\end{array}$ & $\begin{array}{c}\text { Moderate } \\
\text { Difficulty }\end{array}$ & $\begin{array}{c}\text { Extreme } \\
\text { Difficulty }\end{array}$ & $\begin{array}{c}\text { Unable } \\
\text { to do }\end{array}$ & N/A \\
\hline Running & Right & $\square$ & $\square$ & $\square$ & $\square$ & $\square$ & $\square$ \\
& Left & $\square$ & $\square$ & $\square$ & $\square$ & $\square$ & $\square$ \\
\hline Jumping & Right & $\square$ & $\square$ & $\square$ & $\square$ & $\square$ & $\square$ \\
& Left & $\square$ & $\square$ & $\square$ & $\square$ & $\square$ & $\square$ \\
\hline Landing & Right & $\square$ & $\square$ & $\square$ & $\square$ & $\square$ & $\square$ \\
& Left & $\square$ & $\square$ & $\square$ & $\square$ & $\square$ & $\square$ \\
\hline Starting and stopping & Right & $\square$ & $\square$ & $\square$ & $\square$ & $\square$ & $\square$ \\
quickly & Left & $\square$ & $\square$ & $\square$ & $\square$ & $\square$ & $\square$ \\
\hline $\begin{array}{l}\text { Cutting/lateral } \\
\text { movements }\end{array}$ & Right & $\square$ & $\square$ & $\square$ & $\square$ & $\square$ & $\square$ \\
\hline Low impact activities & Left & $\square$ & $\square$ & $\square$ & $\square$ & $\square$ & $\square$ \\
\hline $\begin{array}{l}\text { Ability to perform activity } \\
\text { with your normal }\end{array}$ & Right & $\square$ & $\square$ & $\square$ & $\square$ & $\square$ & $\square$ \\
technique & Left & $\square$ & $\square$ & $\square$ & $\square$ & $\square$ & $\square$ \\
\hline $\begin{array}{l}\text { Ability to participate in } \\
\text { your desired sport as }\end{array}$ & Right & $\square$ & $\square$ & $\square$ & $\square$ & $\square$ & $\square$ \\
\hline \begin{tabular}{l} 
long as you would like \\
\hline
\end{tabular} & Left & $\square$ & $\square$ & $\square$ & $\square$ & $\square$ & $\square$ \\
\hline
\end{tabular}

How would you rate your current level of function during your sports related activities from 0 to 100 with 100 being your level of function prior to your foot or ankle problem and 0 being the inability to perform any of your usual daily activities?

Right: $\quad .0 \%$ Left: $\quad .0 \%$

Overall, how would you rate your current level of function?

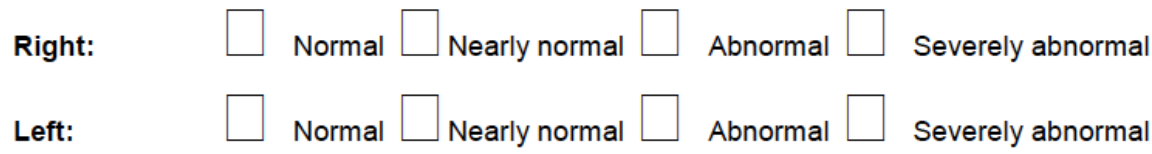

Total FAAM Sport Score: Right: (Clinicians Only) Left: 
1. The subject was sitting in a chair with the hips and knees flexed to 90 degrees.

2. The examiner palpated the head of the talus while the subject moved the foot into pronation and supination to find subtalar neutral (when the talar head depth was palpably the same on both sides).

3. The examiner then palpated to find the navicular tuberosity and marked the position with a washable marker.

4. The height of the navicular tuberosity was then measured by placing an index card on the ground and marking where the navicular drop was $(\mathrm{mm})$.

5. The subject then stood from their chair and the

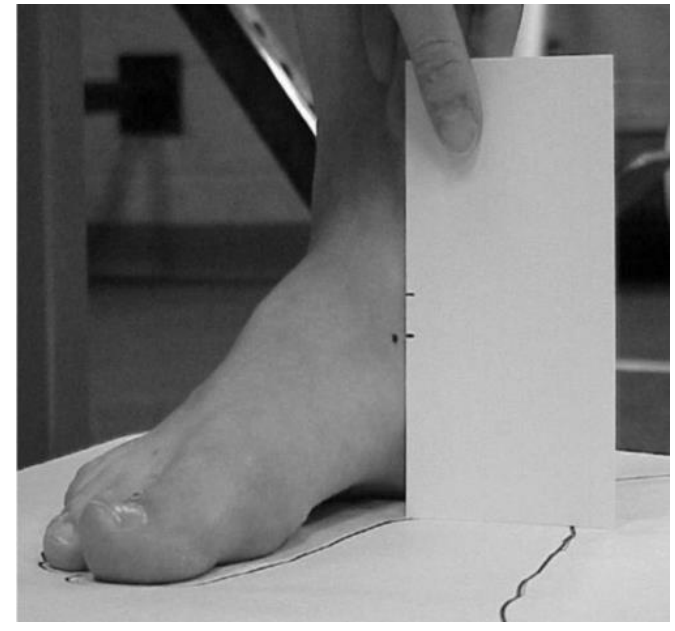
navicular tuberosity was measured again with the same index card (mm).

6. The difference between the two measures were calculated.

7. This was then performed on the other foot.

Table C5 Star Excursion Balance Test43

Anterior

1. The examiner placed white tape on the floor in the shape of a "Y".

2. Leg length of the subject was measured bilaterally from the ASIS to the medial malleolus.

3. The subject stood with hands on hips and the big toe of the stance foot positioned just behind the center of the "Y", which was marked with a line.

4. The subject then reached with the non-stance leg as far as possible in the anterior direction (reach forward). (The subject was granted 2 practice trials and then completed 3 measured trials)

5. The examiner measured each of the 3 trials and used the average for the patient's anterior SEBT.

6. This was then performed with the other leg. 
7. A measurement was not counted when the athlete lost his balance or hands were removed from the hips.

\section{Posteromedial}

1. The examiner placed white tape on the floor in the shape of a "Y".

2. Leg length of the subject was measured bilaterally from the ASIS to the medial malleolus.

3. The subject stood with hands on hips and heel of the stance foot just in front of the center line.

4. The subject then reached with the non-stance leg as far as possible in the posteromedial direction (reach behind). (The subject was granted 2 practice trials and then completed 3 measured trials)

5. The examiner measured each of the 3 trials and used the average for the subject's posteromedial SEBT.

6. This was then performed with the other leg.

7. A measurement was not counted when the athlete lost his balance or hands were removed from the hips.

Posterolateral

1. The examiner placed white tape on the floor in the shape of a "Y".

2. Leg length of the subject was measured bilaterally from the ASIS to the medial malleolus.

3. The subject stood with hands on hips and heel of the stance foot just in front of the center line.

4. The subject then reached with the non-stance leg as far as possible in the posterolateral direction (reach behind). (The subject was granted 2 practice trials and then completed 3 measured trials)

5. The examiner measured each of the 3 trials and used the average for the subject's posterolateral SEBT.

6. This was then performed with the other leg.

7. A measurement was not counted when the athlete lost his balance or hands were removed from the hips. 

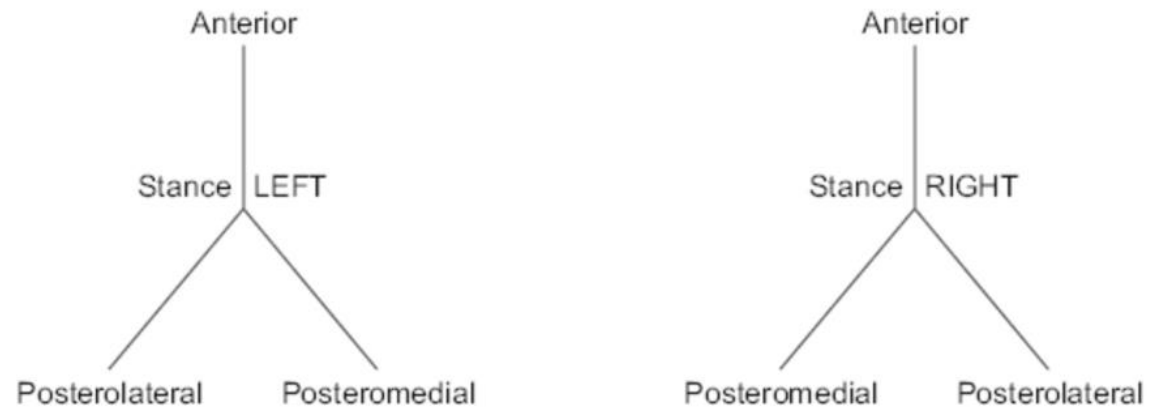

Table C6 Ice Hockey S-Cornering Agility Drill28,50

1. The subject started behind the goal. The time was started upon the first movement of the subject.

2. The subject skated around the first face-off circle.

3. The subject then cross over skated around the other face-off circle in the same zone.

4. The subject then finished at the 1 st blue line. The time was stopped once the 1st skate crossed the blue line. The subject then skated in a half figure 8 pattern around face off dots in a crossover

5. If the subject fell or tripped, he restarted the

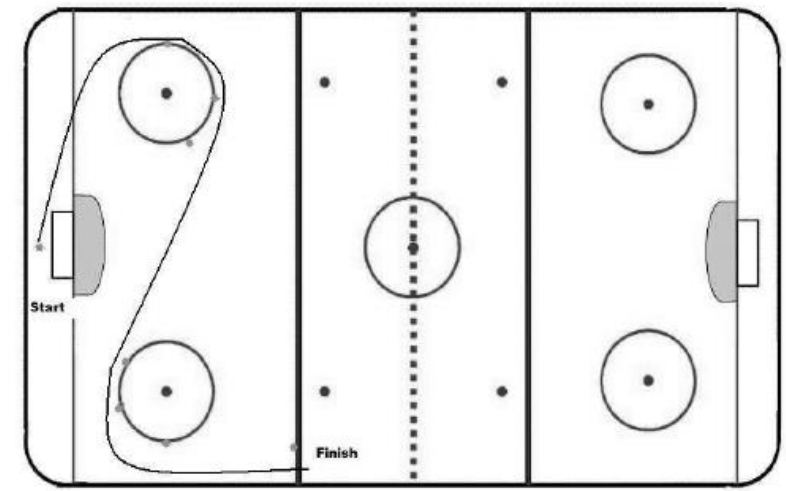
drill

Table C7 Foot Core Interventions

Short Foot Exercise4

1. The subject started seated and was taught to sense when the foot is in the subtalar neutral position by moving the foot from pronation to supination and ending with placing the calcaneus and metatarsal heads on the ground.

2. Once the subject was in subtalar neutral, they were told to create a dome with the foot or raise their arch by drawing the metatarsal heads towards the calcaneus without flexing their toes.

3. The subject held this position for 10 seconds and then relaxed. They completed that contraction ten times for three sets. 
The examiner observed the subject performing this and looked for a drop in navicular position or extrinsic muscle activity. If either of these were noticed the subject was reset and started again.

4. This was progressed each week. The progression consisted of seated, then standing, then to single leg standing with support and finally single leg standing without support.

5. The subject performed this bilaterally.
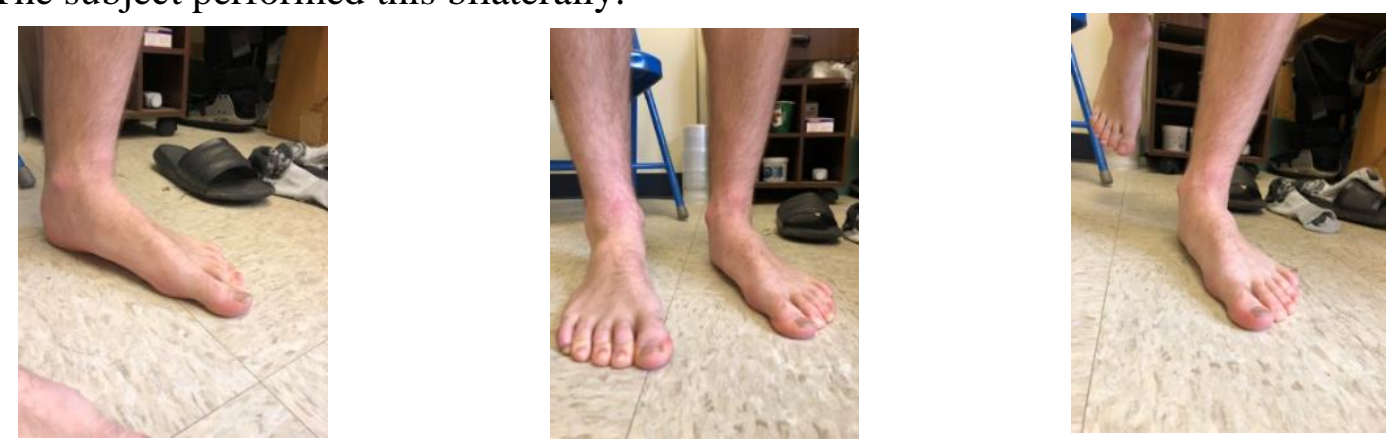

Toes-Spread-Out Exercise 10

1. The subject was in a seated position with feet flat on the floor.

2. The subject was then instructed to extend all 5 toes.

3. The subject was instructed to then abduct all 5 toes.

4. This was progressed each week. The progression consisted of extension and abduction, then extension and abduction while flexing the first toe to the ground, and finally extension and abduction with flexion of both the big toe and 5th toe to the ground.

5. The subject performed this exercise for 3 sets of 10 for each progression.

6. The subject performed this bilaterally and simultaneously.
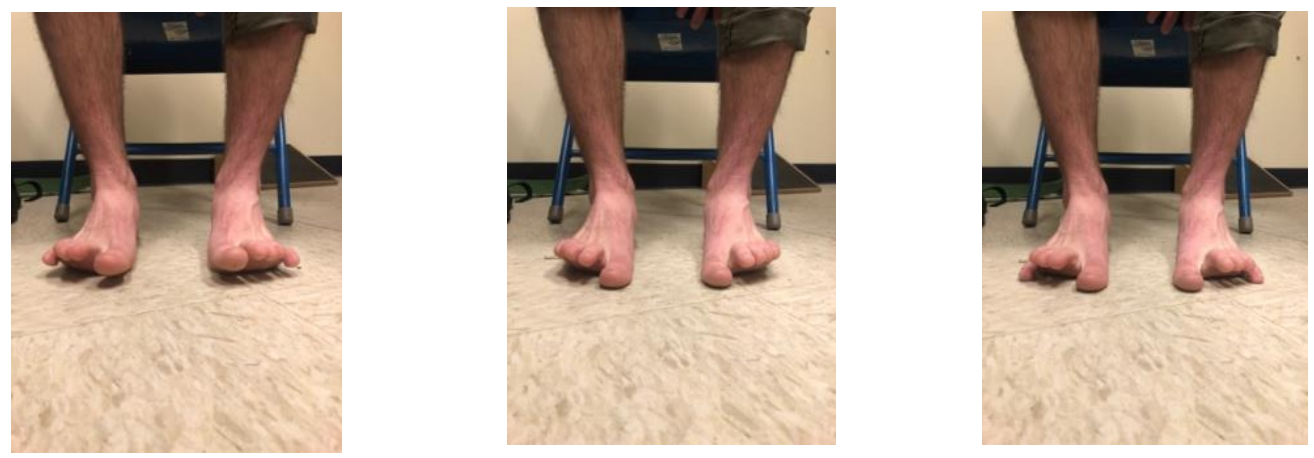


\section{Towel Curl Exercise16}

1. The subject was in a seated position with a towel placed under foot on a slick surface, or tile.

2. The subject then placed the toes on the edge of the towel.

3. The subject was instructed to drag the towel under the foot by flexing their toes.

4. The subject held the grip for 3 seconds during each repetition and dragged the entire towel for 3 sets.

5. The subject performed this bilaterally alternating feet.

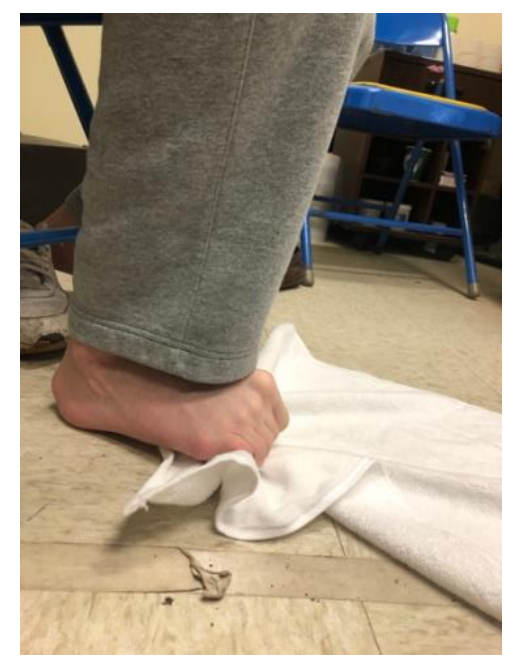

\section{Foam Pick Ups}

1. The subject was in a seated position with 30 pieces of foam placed at the foot.

2. The subject was instructed to pick up each piece of foam individually by flexing their toes and gripping the piece of foam. They then placed the piece of foam into a cup with the foot.

3. The subject was required to pick up every piece of foam, approximately 15 pieces of foam for each foot, for a total of 3 sets.

4. The subject performed this bilaterally, alternating feet.

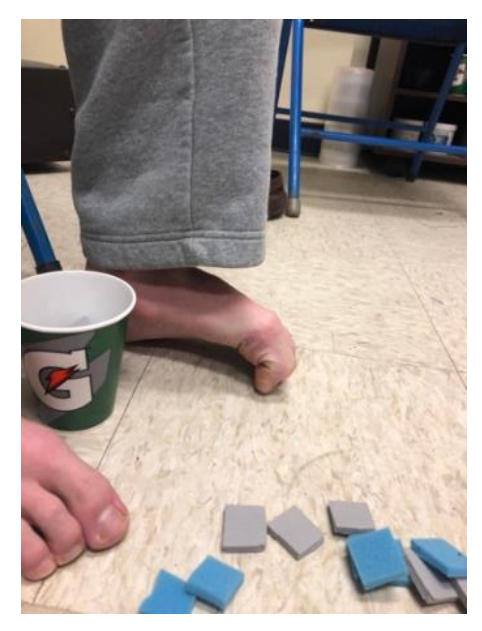


Subject Number:

Age:

Height:

Weight:

Pre-Intervention

$\mathbf{R}$

$\mathbf{L}$

FAAM: ADL

FAAM: Sport

Navicular Drop:

SEBT: Anterior

SEBT: Posteromedial

SEBT: Posterolateral

S-Cornering Agility Drill:

\section{Post-Intervention}

$\mathbf{R}$

$\mathbf{L}$

FAAM: ADL

FAAM: Sport

Navicular Drop:

SEBT: Anterior

SEBT: Posteromedial

SEBT: Posterolateral

S-Cornering Agility Drill 


\section{APPENDIX D}

\section{ADDITIONAL RESULTS}

Table D1. Self-Reported Function Scores (Means \pm SD) and Hedges g Group Effect Sizes With 95\% Confidence Intervals

\begin{tabular}{llllll}
\hline Variable & \multicolumn{2}{c}{ FC } & \multicolumn{3}{c}{ Traditional } \\
FAAM Sport\% (L) & $100 \pm 0$ & \multicolumn{1}{c}{ Post-Test } & Pre-Test & \multicolumn{1}{c}{ Post-Test } & GE \\
FAAM ADL\% (L) & $99.79 \pm .58$ & $99.79 \pm .80$ & $98.17 \pm 4.78$ & $98.42 \pm 5.48$ & $.25(-.52$ to 1.02$)$ \\
FAAM Sport\% (R) & $99.14 \pm 3.21$ & $99.79 \pm .80$ & $98.67 \pm 3.23$ & $99 \pm 3.46$ & $.21(-.57$ to .98$)$ \\
FAAM ADL\% (R) & $99.36 \pm 1.65$ & $99.5 \pm 1.61$ & $98.17 \pm 4.78$ & $98.42 \pm 5.48$ & $.25(-.52$ to 1.02$)$ \\
\hline KA & $98.67 \pm 3.23$ & $98.67 \pm 3.55$ & $.23(-.54$ to 1.01$)$
\end{tabular}

Key: FAAM= Foot and Ankle Ability Measure (percent); ADL=Activities of Daily Living; FC = Foot Core; L = left; R = right; Time and Group reflect Main Effects with P value and Group x Time reflects Interaction with P value; GE= Group effect calculated from each group's pretest-to-posttest change score divided by each group's pooled standard deviation; Effect size - small (<.4), moderate (.41-.70) and large (>.71)

Table D2. Navicular Drop, Star Excursion Balance Test, and Agility (Means \pm SD) and Hedges g Group Effect Sizes With 95\% Confidence Intervals

\begin{tabular}{|c|c|c|c|c|c|c|c|c|c|}
\hline \multirow[t]{2}{*}{ Variable } & \multicolumn{2}{|l|}{$\mathrm{FC}$} & \multicolumn{2}{|c|}{ Traditional } & \multirow[b]{2}{*}{ Limb } & \multirow[b]{2}{*}{ Test } & \multirow[b]{2}{*}{ Test x Group } & \multirow[b]{2}{*}{ Limb $\times$ Test } & \multirow[b]{2}{*}{ GE } \\
\hline & Pre-Test & Post-Test & Pre-Test & Post-Test & & & & & \\
\hline ND: Left & $7.29 \pm 3.05$ & $4.04 \pm 2.73$ & $8.5 \pm 2.65$ & $6.25 \pm 2.14$ & & $<.001$ & & & $-.02(-1.85$ to -.85$)$ \\
\hline ND: Right & $6.43 \pm 3.84$ & $4.71 \pm 1.89$ & $7.75 \pm 2.49$ & $5.25 \pm 2.22$ & & $<.001$ & & & $-.24(-1.84$ to -.2$)$ \\
\hline \multicolumn{10}{|l|}{ SEBT: Left } \\
\hline A & $75.13 \pm 8.7$ & $74.18 \pm 6.33$ & $67.6 \pm 7.26$ & $72.27 \pm 7.22$ & .032 & & .024 & & $.26(-.51$ to 1.04$)$ \\
\hline PM & $93.73 \pm 12.39$ & $100.66 \pm 11.84$ & $86.37 \pm 10.62$ & $95.89 \pm 9.19$ & & $<.001$ & & .031 & $.52(-.26$ to 1.3$)$ \\
\hline PL & $75.75 \pm 8.16$ & $85.12 \pm 9.94$ & $76.71 \pm 10.52$ & $84.52 \pm 11.16$ & & .001 & & & $.05(-.72$ to .82$)$ \\
\hline \multicolumn{10}{|c|}{ SEBT: Right } \\
\hline A & $73.97 \pm 11.31$ & $71.42 \pm 8.91$ & $67.44 \pm 8.89$ & $71.05 \pm 7.27$ & .032 & & .024 & & $.5(-.72$ to .82$)$ \\
\hline PM & $96.17 \pm 11.82$ & $100.89 \pm 11.41$ & $87.42 \pm 10.05$ & $93.38 \pm 9.69$ & & $<.001$ & & .031 & $.78(-.02$ to 1.57$)$ \\
\hline PL & $77.65 \pm 7.89$ & $83.60 \pm 8.93$ & $74.60 \pm 12.46$ & $79.81 \pm 10.71$ & & .001 & & & $.35(-.42$ to 1.13$)$ \\
\hline Agility & $8.97 \pm .78$ & $8.51 \pm .96$ & $9.01 \pm 1.12$ & $8.41 \pm 1.16$ & & $<.001$ & & & $.09(-.7$ to .87$)$ \\
\hline
\end{tabular}

Key: *ND = Navicular Drop; SEBT= Star Excursion Balance Test (normalized reach distances); A= Anterior; PM= Posterior Medial; PL= Posterior Lateral; FC

$=$ Foot Core; Time and Group reflect Main Effects with P value and Group x Time reflects Interaction with P value; GE= Group effect calculated from each group's pretest-to-posttest change score divided by each group's pooled standard deviation; Effect size - small (<.4), moderate (.41-.70) and large (>.71) 


\section{APPENDIX E \\ RECOMMENDATIONS FOR FUTURE RESEARCH}

1. Increase the number of subjects within each exercise group by utilizing multiple site locations and multiple recreational ice hockey teams to verify the results of this study.

2. Utilize an independent assessor, blinded to group allocation, to collect and record baseline and follow-up data to help researcher.

3. Increase the length of the study to a four-week follow up time periods after the intervention ends to analyze whether beneficial results remain.

4. Conduct a prospective study as a pre-season performance enhancement program utilizing foot core and traditional exercises each year, and then perform a longitudinal study to examine performances for the season and successive years.

5. Conduct the study in a controlled laboratory setting or in an undisturbed, restricted area that can allow the subjects to be separated by group during the performance of exercises.

6. Conduct the study with ice hockey athletes who have a history of lower extremity injuries (foot, ankle, knee, and hip) within the past 6 months to examine the impacts on perceived ability, agility, balance and foot posture.

7. Conduct a study to observe the effect of traditional and foot core exercise intervention on foot posture, agility and balance using the following ice hockey populations: youth, high school, elite or professional level.

8. Conduct a biomechanical study focusing on which side of the skate the ice hockey players are primarily on while skating; medial or lateral.

9. Conduct the study to evaluate the impacts these exercise programs have on ice hockey athletes when combined with other techniques (i.e. balance programs, full body strengthening, etc.). 


\section{ADDITIONAL REFERENCES}

30. Nakayama Y, Tashiro Y, Suzuki Y, Kajiwara Y, Zeidan H, Kawagoe M, et al. Relationship between transverse arch height and foot muscles evaluated by ultrasound imaging device. $J$ Phys Ther Sci. 2018;30(4):630-635.

31. Nakhaee Z, Rahimi A, Abaee M, Rezasoltani A, Khademi Kalantari K. The relationship between the height of the medial longitudinal arch (MLA) and the ankle and knee injuries in professional runners. Foot. 2008:84-90.

32. Zelik KE, La Scaleia V, Ivanenko YP, Lacquaniti F. Coordination of intrinsic and extrinsic foot muscles during walking. Eur J Appl Physiol. 2015;115:691-701.

33. Cech P. Effect of short-term balance training on postural stability in ice hockey players. Kinanthropologica. 2014;50(2):13-20.

34. Ridge ST, Myrer JW, Olsen MT, Jurgensmeier K, Johnson AW. Reliability of doming and toe flexion testing to quantify foot muscle strength. J Foot Ankle Res. 2017;10(55):1-7.

35. Card RK and Bordoni B. Anatomy, bony pelvis and lower limb, foot muscles. NCBI. 2019.

36. Drake M, Bittenbender C, Boyles R. The short-term effects of treating plantar fasciitis with a temporary custom foot orthosis and stretching. J Orthop Sports Phys Ther. 2011;41(4):221231.

37. Deussen S and Alfuth M. The influence of sensorimotor training modalities on balance, strength, joint function, and plantar foot sensitivity in recreational athletes with a history of ankle sprain: A randomized controlled pilot study. Int J Sports Phys Ther. 2018;13(6):9931007.

38. Nurse MA and Nigg BM. Quantifying a relationship between tactile and vibration sensitivity of the human foot with plantar pressure distributions during gait. Clin Biomech.

1999;14(9):667-672.

39. Miller EE, Whitcome KK, Lieberman DE, Norton HL, Dyer RE. The effect of minimal shoes on arch structure and intrinsic foot muscle strength. J Sport Health Sci. 2014;(3):74-85.

40. Takashi S. Effect of the towel curl exercise on the medial longitudinal arch of the foot. Phys Ther Sport. 2017;28.

41. Chung KA, Lee E, Lee S. The effect of intrinsic foot muscle training on medial longitudinal arch and ankle stability in patient with chronic ankle sprain accompanied by foot pronation. Phys Ther Rehabil Sci. 2016;5(2):78-83. 
42. Hall EA, Docherty CL, Simon J, Kingma JJ, Klossner JC. Strength-training protocols to improve deficits in participants with chronic ankle instability: A randomized control trial. $J$ Athl Train. 2015;50(1):36-44.

43. Hale SA, Fergus A, Axmacher R, Kiser K. Bilateral improvements in lower extremity function after unilateral balance training in individuals with chronic ankle instability. $J$ Ath $l$ Train. 2014;49(2):181-191.

44. Headlee DL, Leonard JL, Hart JM, Ingersoll CD, Hertel J. Fatigue of the plantar intrinsic foot muscles increases navicular drop. J Electromyo Kines. 2008;18:420-425.

45. Cheung RTH, Sze LKY, Mok NW, Ng GYF. Intrinsic foot muscle volume in experienced runners with and without chronic plantar fasciitis. J Sci Med Sport. 2016;19:713-715.

46. Donovan L, Hart JM, Saliba SA, Park J, Feger MA, Herb CC, Hertel J. Rehabilitation for chronic ankle instability with or without destabilization devices: A randomized control trial. J Athl Train. 2016;51(3):233-251.

47. Kim TG and So WY. Effect of functional rehabilitation exercise on chronic ankle instability in elite athletes. S Afr J Res Sport PH. 2015;37(2):47-60.

48. Gribble PA, Kelly SE, Refshauge KM, Hiller CE. Interrater reliability of the star excursion balance test. J Athl Train. 2013;48(5):621-626.

49. Buchanan KR and Davis IS. The relationship between forefoot, midfoot, and rearfoot static alignment in pain-free individuals. J Orthop Sports Phys Ther. 2005;35(9):559-566.

50. Sandrey and Games. Test Re-test Reliability of on-Ice Exercises for Functional Ice Hockey Return to Play Battery. 